\title{
The Ubiquitin E3 Ligase TRAF6 Exacerbates Ischemic Stroke by Ubiquitinating and Activating Rac1
}

\author{
Tao Li, ${ }^{1}$ - Juan-Juan Qin, ${ }^{2,3,4,5}$ @Xia Yang, ${ }^{2,3,4,5}$ Yan-Xiao Ji, ${ }^{2,3,4,5}$-Fangliang Guo, ${ }^{1}$ Wen-Lin Cheng, ${ }^{2,3,4,5}$ Xiaolin Wu, \\ Fu-Han Gong, ${ }^{2}$ Ying Hong, ${ }^{2,3,4,5} \odot$ Xue-Yong Zhu, ${ }^{2,3,4,5}$ Jun Gong, ${ }^{3,4,5,6}$ Zhihua Wang, ${ }^{2,3,4,5}{ }^{\circ}$ Zan Huang, ${ }^{3,4,5,6}$ \\ Zhi-Gang She, $2,3,4,5$ and Hongliang $\mathrm{Li}^{2,3,4,5}$ \\ ${ }^{1}$ Department of Neurology and ${ }^{2}$ Department of Cardiology, Renmin Hospital, ${ }^{3}$ Basic Medical School, ${ }^{4}$ Institute of Model Animal, ${ }^{5}$ Medical Research \\ Institute, School of Medicine, ${ }^{6}$ College of Life Science, and ${ }^{7}$ Department of Neurosurgery, Zhongnan Hospital, Wuhan University, Wuhan 430060, China
}

Stroke is one of the leading causes of morbidity and mortality worldwide. Inflammation, oxidative stress, apoptosis, and excitotoxicity contribute to neuronal death during ischemic stroke; however, the mechanisms underlying these complicated pathophysiological processes remain to be fully elucidated. Here, we found that the expression of tumor necrosis factor receptor-associated factor 6 (TRAF6) was markedly increased after cerebral ischemia/reperfusion (I/R) in mice. TRAF6 ablation in male mice decreased the infarct volume and neurological deficit scores and decreased proinflammatory signaling, oxidative stress, and neuronal death after cerebral I/R, whereas transgenic overexpression of TRAF6 in male mice exhibited the opposite effects. Mechanistically, we demonstrated that TRAF6 induced Racl activation and consequently promoted I/R injury by directly binding and ubiquitinating Racl. Either functionally mutating the TRAF6 ubiquitination site on Rac1 or inactivating Racl with a specific inhibitor reversed the deleterious effects of TRAF6 overexpression during I/R injury. In conclusion, our study demonstrated that TRAF6 is a key promoter of ischemic signaling cascades and neuronal death after cerebral I/R injury. Therefore, the TRAF6/Racl pathway might be a promising target to attenuate cerebral I/R injury.

Key words: ischemic stroke; molecular mechanism; Rac1; therapy; TRAF6; ubiquitinating

Significance Statement

Stroke is one of the most severe and devastating neurological diseases globally. The complicated pathophysiological processes restrict the translation of potential therapeutic targets into medicine. Further elucidating the molecular mechanisms underlying cerebral ischemia/reperfusion injury may open a new window for pharmacological interventions to promote recovery from stroke. Our study revealed that ischemia-induced tumor necrosis factor receptor-associated factor 6 (TRAF6) upregulation binds and ubiquitinates Racl directly, which promotes neuron death through neuroinflammation and neuro-oxidative signals. Therefore, precisely targeting the TRAF6-Racl axis may provide a novel therapeutic strategy for stroke recovery.

\section{Introduction}

Cerebral stroke kills $>5$ million people annually worldwide and is one of the leading causes of long-term disability in adults in

Received June 22, 2017; revised Sept. 19, 2017; accepted 0ct. 27, 2017.

Author contributions: H.L., J.-J.Q., Z.-H.W., Z.H., and Z.-G.S. designed research; T.L., X.Y., Y.-X.J., F.G., X.W., F.-H.G., Y.H., X.-Y.Z., and J.G. performed research; J.-J.Q. and W.-L.C. analyzed data; J.-J.Q. and Z.-G.S. wrote the paper.

This work was supported bythe National Science Fund for Distinguished Young Scholars (Grant 81425005), the Key Project of the National Natural Science Foundation (Grants 81330005 and 91639304), the National Natural Science Foundation of China (Grants 81370209, 81370365, 81270184, 31371481, and 81271364), the National Science and Technology Support Project (Grants 2013YQ030923-05, 2014BAI02B01, 2015BAI08B01, and 2016YFF0101500), the China Postdoctoral Science Foundation (Grant 2016M600617), and the Wuhan Science and Technique Foundation (Grant 201306062010270).

The authors declare no competing financial interests.

Correspondence should be addressed to either of the following: Zhi-Gang She, M.D., Ph.D., Professor, Department of Cardiology, Renmin Hospital of Wuhan University, Luojia Mount Wuchang, Wuhan; 430072, China, E-mail: zgshe@whu.edu.cn; or Hongliang Li, M.D., Ph.D., School of Basic Medical Science, Wuhan University, Institute of Model Animal, Wuhan University, Animal Research Center, Wuhan University, Medical Research Institute, Zhongnan developed societies (Bonita, 1992; Lozano et al., 2012). Approximately $80 \%$ of strokes are ischemic (Feigin et al., 2003; Humphries and Morgan, 2004). Tissue plasminogen activator (TPA) is the only U.S. Food and Drug Administration-approved therapeutic treatment for ischemic stroke; however, only $20 \%$ of stroke patients receive this treatment because of its narrow therapeutic window ( $<4.5 \mathrm{~h}$ after onset of stroke symptoms) and its association with an increased risk of symptomatic intracerebral hemorrhage. Furthermore, the recanalization rate of patients receiving TPA is $<50 \%$ (Tobin et al., 2014). Therefore, alternative treatments for ischemic stroke based on a more thorough understanding of its molecular mechanisms are urgently needed.

Hospital, Cardiovascular Research Institute, Wuhan University, Luojia Mount Wuchang, Wuhan 430072, China E-mail: lihl@whu.edu.cn.

DOI:10.1523/JNEUROSCI.1751-17.2017

Copyright $\odot 2017$ the authors $\quad 0270-6474 / 17 / 3712123-18 \$ 15.00 / 0$ 
The basic pathophysiology of ischemic stroke is neuronal death (Khoshnam et al., 2017), which is accompanied/induced by inflammation, oxidative stress, and excitotoxicity after ischemia (Broughton et al., 2009; Moskowitz et al., 2010; Iadecola and Anrather, 2011). After ischemia, glutamate immediately accumulates at synapses, followed by drastically enhanced calcium influx into neurons and the onset of catabolic processes (Ankarcrona et al., 1995; Lo et al., 2003). The high level of calcium in ischemic cells triggers the production of oxygen radicals, which directly damage lipids, proteins, nucleic acids, and carbohydrates (Lo et al., 2003). The inflammatory response and apoptosis, both of which are critical to determining cell fate in the penumbra, typify the secondary or delayed response to focal ischemia (Broughton et al., 2009; Moskowitz et al., 2010b; Iadecola and Anrather, 2011). Complex signaling networks such as the mitogenactivated protein kinase (MAPK), phosphatidylinositol 3-kinase/ Akt (PI3K/Akt), nuclear factor- $\kappa \mathrm{B}$ (NF- $\kappa \mathrm{B})$, Janus-activated kinase/signal transducer and activator of transcription 3 (JAK2/ STAT3), and NADPH oxidase 2 (Nox2) cascades, as well as Rac1 signaling have been implicated in this process (Moskowitz et al., 2010; Tymianski, 2011; Tang et al., 2011; Fann et al., 2017). Despite these discoveries, the fundamental mechanisms underlying ischemia/reperfusion (I/R) injury of the brain remain unclear. Therefore, a better understanding of the pathogenesis of ischemic stroke and the identification of novel therapeutic targets are required for improving treatment.

The tumor necrosis factor receptor (TNFR)-associated factor (TRAF) family members (TRAF1-7 in mammals), which are characterized by an N-terminal RING finger motif (except TRAF1) and a C-terminal TRAF domain (except TRAF7), are important adaptor proteins in the assembly of receptor-associated signaling networks that link upstream receptors to downstream effector molecules. Recently, we and others have revealed the functions of TRAF1/2/3/5 in ischemic stroke (Wang et al., 2013; Lu et al., 2013; Geng et al., 2015; Su et al., 2017). In contrast to other TRAFs, TRAF6 uses a distinct interaction motif presented in its upstream activators (Ye et al., 2002). TRAF6 has indispensable roles in regulating host immunity, embryonic development, tissue homeostasis, and neurodegenerative disease (Zucchelli et al., 2011; Xie, 2013). TRAF6 expression has been reported to be upregulated in the peripheral blood of ischemic stroke patients, as well as in neurons from a rat model of cerebral I/R (Wu et al., 2013; Yuan et al., 2013; Su et al., 2015). Nevertheless, the potential role and the underlying mechanism of TRAF6 in ischemic stroke remain unknown.

In this study, we identified neuronal TRAF6 as a key modulator of the ischemic signaling cascades that promote the development of cerebral I/R-induced inflammation, oxidative stress, and neuronal loss. Mechanistically, TRAF6 interacts directly with Rac1 and promotes its Lys63-linked ubiquitination, thereby promoting and maintaining the activation of Racl. Activated Rac1 then stimulates NF- $\kappa$ B-mediated inflammation, NAPDH oxidase-mediated oxidative stress, and neuronal cell death after cerebral I/R injury.

\section{Materials and Methods}

Animals. All experimental protocols were approved by the Animal Care and Use Committee of Renmin Hospital of Wuhan University and were conducted in accordance with the National Institutes of Health's Guide for the Care and Use of Laboratory Animals. TRAF6 floxed mice (C57BL/6J background) were generated as described previously (Ji et al., 2016). Neuronspecific TRAF6-knock-out mice were then generated by breeding the TRAF6 floxed mice with CaMKII $\alpha$-Cre mice (Casanova et al., 2001).
Table 1. Antibodies used for immunofluorescence

\begin{tabular}{lllll}
\hline Antibody & Manufacturer & Catalog\# & Sources of species & RRID \\
\hline Traf6 & Abcam & ab40675 & Rabbit & AB_778573 \\
NeuN & Millipore & MAB353 & Mouse & AB_94911 \\
MAP2 & Abcam & Ab5392 & Chicken & AB_2138153 \\
PCNA & Abcam & ab92552 & Rabbit & AB_2138153 \\
4-HNE & Abcam & Ab48506 & Mouse & AB_867452 \\
8-OHDG & Santa & sc66036 & Mouse & AB_832272 \\
p-Rac1/cdc42(Ser71) & CST & 24615 & Rabbit & AB_2300703 \\
\hline
\end{tabular}

Transgenic mice with neuron-specific expression of either WT TRAF6 or mutant TRAF6 (C70A) were generated by cloning the full-length mouse TRAF6 cDNA or the TRAF6 (C70A) mutant cDNA downstream of the neuron-specific promoter platelet-derived growth factor B-chain (PDGF $\beta$ ) (Peel et al., 1997; Kuteeva et al., 2004). The linearized plasmid was then microinjected into fertilized mouse embryos to produce mice with neuron-specific TRAF6 expression and the mice were identified through PCR analysis of tail genomic DNA. The PCR primers used were as follows: forward, 5' -CTGAAAGGGTGGCAACTTCT-3' and reverse, 5'-CTGGCACTTCTGGAAAGGAC-3'.

Cerebral ischemia/reperfusion induced by surgical middle cerebral artery occlusion (MCAO). Cerebral ischemia was induced by occlusion of the left middle cerebral artery (MCA) using the intraluminal filament technique. Briefly, male mice aged 11-12 weeks (25-30 g) were subjected to inhalational anesthesia with $2.5-3 \%$ isoflurane in $\mathrm{O}_{2}$ and a heating plate was used to maintain the rectal temperature at $37 \pm 0.5^{\circ} \mathrm{C}$. MCAO was achieved by introducing a 6-0 silicon-coated monofilament (Doccol) into the internal carotid artery through an incision in the left common carotid artery. The filament was then advanced into the circle of Willis to obstruct the origin of the MCA. Doppler analysis (PeriFlux System 5010; Perimed) was used to evaluate the blockage and restoration of regional cerebral blood flow (rCBF). The filament was withdrawn after $45 \mathrm{~min}$ of $\mathrm{MCAO}$ and $\mathrm{rCBF}$ was restored for the durations indicated. The animals were returned to warm cages for $2 \mathrm{~h}$ for recovery with ad libitum access to food and water. For the sham group, the filament was immediately withdrawn after the rCBF diminished. The blood gases, systolic blood pressure, diastolic blood pressure, and heart rate were recorded in randomly selected conscious mice.

Treatment with a Rac1 inhibitor. The Rac1-specific inhibitor NSC23766 (Sigma-Aldrich) was dissolved in dimethyl sulfoxide (DMSO) (5 mM) diluted in phosphate buffer solution. The NSC23766 was intracranially injected into wild-type (WT) and TRAF6-TG mice (10 mg/kg) (Raz et al., 2010; Liao et al., 2014; Meng et al., 2015) $1 \mathrm{~h}$ after MCAO. DMSO of the same volume was injected intracranially as a control treatment.

Neurological deficit scores. Neurological deficits were evaluated by using a nine-point scale at 24 and $72 \mathrm{~h}$ after MCAO induction on the basis of the following criteria: (1) absence of neurological deficits (0 points); (2) either left forelimb flexion after suspension by the tail or failure to fully extend the right forepaw (1 point); (3) left shoulder adduction after suspension by the tail ( 2 points); (4) decreased resistance to a lateral push toward the left (3 points); (5) spontaneous movement in all directions with circling to the left only if pulled by the tail (4 points); (6) spontaneously circling or walking only to the left (5 points); (7) walking only when stimulated (6 points); (8) no response to stimulation (7 points); and (9) stroke-related death (8 points).

Infarct volume determination. At the indicated times ( 24 and $72 \mathrm{~h}$ ) after $\mathrm{MCAO} /$ reperfusion, the brains were removed and sliced into $71 \mathrm{~mm}$ coronal sections, which were immersed in a $2 \% 2,3,5$-triphenyl- $2 \mathrm{H}$ tetrazolium chloride solution for $15 \mathrm{~min}$ at $37^{\circ} \mathrm{C}$. Normal brain tissue was stained a red color, whereas infarcted tissue stained a pale gray color. The sections were photographed and analyzed using Image-Pro Plus 6.0 (Media Cybernetics) and the infarct volume (percentage) of the seven slices was calculated after correcting for edema as described previously (Lu et al., 2013).

Histopathological evaluation. For histopathological evaluation, the mice were anesthetized and transcardially perfused with $0.1 \mathrm{M}$ sodium phosphate buffer, $\mathrm{pH} 7.4$, followed by $4 \%$ paraformaldehyde in phos- 
Table 2. Primers used for real-time PCR

\begin{tabular}{|c|c|}
\hline Gene & Sequence $5^{\prime}$ to $3^{\prime}$ \\
\hline \multicolumn{2}{|l|}{ Fas } \\
\hline Forward & ACCATACCAATGAATGCCTCAA \\
\hline Reverse & TCTGCTCAGCTGTGTCTTGG \\
\hline \multicolumn{2}{|l|}{ Fas1 } \\
\hline Forward & AAGCAGCAGCCTGAGAGTATC \\
\hline Reverse & CTGTTCTCCAGCTCCCGTTC \\
\hline \multicolumn{2}{|l|}{ Bax } \\
\hline Forward & CTGGATCCAAGACCAGGGTG \\
\hline Reverse & TCTTCCAGATGGTGAGCGAG \\
\hline \multicolumn{2}{|l|}{ Bad } \\
\hline Forward & TTAGCCCTTTTCGAGGACGC \\
\hline Reverse & CGCTTTGTCGCATCTGTGTT \\
\hline \multicolumn{2}{|l|}{$\mathrm{BCl} 2$} \\
\hline Forward & GAACTGGGGGAGGATTGTGG \\
\hline Reverse & GCATGCTGGGGCCATATAGT \\
\hline \multicolumn{2}{|l|}{ TNF- $\alpha$} \\
\hline Forward & TGACAAGCCTGTAGCCCAC \\
\hline Reverse & TAGCAAATCGGCTGACGGTG \\
\hline \multicolumn{2}{|l|}{ MCP-1 } \\
\hline Forward & САCTCACCTGCTGCTACTCA \\
\hline Reverse & СTTCTTGGGGTCAGCACAGA \\
\hline \multicolumn{2}{|l|}{ IL-1 $\beta$} \\
\hline Forward & TAATGAAAGACGGCACACCCA \\
\hline Reverse & GTTTCCCAGGAAGACAGGCT \\
\hline \multicolumn{2}{|r|}{ (17. } \\
\hline Forward & ATGAACTTGGACCTCTGCGG \\
\hline Reverse & GTCCACCACAGTTGCTGACT \\
\hline \multicolumn{2}{|l|}{ VACM-1 } \\
\hline Forward & GCACTTGTGGAAATGTGCCC \\
\hline Reverse & AGATGCGCAGTAGAGTGCAA \\
\hline \multicolumn{2}{|l|}{ ICAM-1 } \\
\hline Forward & AAGAGGGGTCTCAGCAGACT \\
\hline Reverse & CATCACGAGGCCCACAATGA \\
\hline \multicolumn{2}{|r|}{ (2) } \\
\hline Forward & TCAGGCCCAGTCCCTCAATA \\
\hline Reverse & TCCAGCGAGGAGATCGATGA \\
\hline \multicolumn{2}{|r|}{ (2) } \\
\hline Forward & GTGGGGGCTTTGTGCCTAAT \\
\hline Reverse & CCAGCGGATGTCATGGATCT \\
\hline \multicolumn{2}{|l|}{ Txn-1 } \\
\hline Forward & TGTTGCTGCAGACTGTGAAGT \\
\hline Reverse & AAGCTTTTCCTTGTTAGCACCG \\
\hline \multicolumn{2}{|l|}{ SOD2 } \\
\hline Forward & AGGAGCAAGGTCGCTTACAG \\
\hline Reverse & TGCTCCCACACGTCAATCC \\
\hline \multicolumn{2}{|l|}{ SOD3 } \\
\hline Forward & TTCTACGGCTTGCTACTGGC \\
\hline Reverse & TGCGTGTCGCCTATCTTCTC \\
\hline \multicolumn{2}{|l|}{ p47-phox } \\
\hline Forward & AGAGCATCCACCAGCGTTC \\
\hline Reverse & GCTTCCGTTTGGTGCTCTCT \\
\hline \multicolumn{2}{|l|}{ p67-phox } \\
\hline Forward & GGGAAAACTCAGACGCCAGT \\
\hline \multirow{2}{*}{\multicolumn{2}{|c|}{$\begin{array}{r}\text { Reverse } \\
\text { gp1-phox }\end{array}$}} \\
\hline & \\
\hline Forward & ATAGCTACTGCCCACCCCAA \\
\hline Reverse & TCCAGACTGGAGTATCGCTGA \\
\hline
\end{tabular}

phate buffer for $15 \mathrm{~min}$. The brains were harvested and fixed in $4 \%$ paraformaldehyde solution for $6-8 \mathrm{~h}$ at room temperature. The brains were then immersed overnight at $4^{\circ} \mathrm{C}$ in phosphate buffer containing $30 \%$ sucrose and embedded in optimal cutting temperature (OCT) solution. The OCT-embedded brains were sliced into 5 - $\mu \mathrm{m}$-thick sections. In addition, primary neurons cultured on coverslips were fixed in icecold acetone. The cryosections and coverslips were then washed in PBS
Table 3. Antibodies used for immunoblot analyses

\begin{tabular}{|c|c|c|c|c|}
\hline Antibody & Manufacturer & Catalog\# & Sources of species & RRID \\
\hline TRAF6 & Abcam & Ab40675 & Rabbit & $A B \_778573$ \\
\hline Bax & CST & 2772 & Rabbit & AB_329921 \\
\hline $\mathrm{BCl}-2\left(50 \mathrm{E}_{3}\right)$ & CST & 2870 & Rabbit & $A B \_2290370$ \\
\hline Cleaved Caspase3(Asp175) & CST & 9661 & Rabbit & $A B \_2341188$ \\
\hline Caspase-3 & CST & 9662 & Rabbit & $A B \_331439$ \\
\hline p-lkBa(ser32/36) & CST & 9246L & Mouse & AB_2267145 \\
\hline $\operatorname{lkBa}(\mathrm{L} 35 \mathrm{~A} 5)$ & CST & 4814 & Mouse & AB_390781 \\
\hline P-lkk $\beta(Y 199)$ & Abcam & Ab59195 & Rabbit & $A B \_943810$ \\
\hline IKK $\beta$ & CST & 89435 & Rabbit & AB_11024092 \\
\hline P-NF-kB p65(Ser536) & CST & 3033 & Rabbit & $A B \_331284$ \\
\hline p65 - & CST & 4764 & Rabbit & $A B \_823578$ \\
\hline P47-phox(P366) & Bioworld & BS3261 & Rabbit & AB_1662897 \\
\hline N0XA2/P67 phox & Abcam & Ab109366 & Rabbit & AB_10860640 \\
\hline SD1(SOD1) & Abcam & Ab13498 & Rabbit & $A B \_300402$ \\
\hline Heme 0xygenase 1(H0-1) & Abcam & Ab13243 & Rabbit & AB_299790 \\
\hline p-Rac1/cdc42(Ser71) & CST & 24615 & Rabbit & $A B \_2300703$ \\
\hline $\operatorname{Rac} 1 / 2 / 3$ & CST & 2467 & Rabbit & $A B \_2176150$ \\
\hline $\mathrm{HA}$ & Sigma-Aldrich & H6908 & Rabbit & $A B \_260070$ \\
\hline Flag & Sigma-Aldrich & F3165 & Mouse & $A B \_259529$ \\
\hline Myc & $\mathrm{MBL}$ & M192-3 & Mouse & $A B \_11160947$ \\
\hline Ub & CST & 39335 & Rabbit & $A B \_2180538$ \\
\hline His & CST & 12698 & Rabbit & \\
\hline Gst & CST & 26245 & Mouse & AB_10692101 \\
\hline GAPDH(14C10) & CST & 2118 & Rabbit & $A B \_561053$ \\
\hline
\end{tabular}

containing $10 \%$ goat serum and incubated overnight at $4^{\circ} \mathrm{C}$ with primary antibodies. Antibodies are listed in Table 1. After the sections were washed in PBS, they were incubated with the indicated secondary antibodies for $1 \mathrm{~h}$. Goat anti-chicken IgY (H\&L, DyLight 488, ab96947; Abcam), Alexa Fluor 568-conjugated goat anti-mouse IgG (A11004; Invitrogen), and Alexa Fluor 568-conjugated anti-rabbit IgG (A11011; Invitrogen) secondary antibodies were used, whereas 406-diamino-2phenylindole (S36939; Invitrogen) was used to stain nuclei. In addition, an ApopTag Plus In Situ Apoptosis Fluorescein Detection Kit (S7111; Millipore) was used to conduct the TUNEL assay according to the manufacturer's protocol. TUNEL-positive cells were evaluated using a microscope and quantified under high-power magnification $(200 \times)$.

Quantitative real-time PCR and Western blotting. Tissues used for quantitative real-time PCR and Western blot analysis were obtained as follows. Brains were transcardially perfused with cold sodium phosphate before removal and the olfactory bulbs and $1 \mathrm{~mm}$ sections of the anterior and posterior brain tissue were excised. The remaining tissues of the ipsilateral (including the infarcted and peri-infarcted areas) and contralateral (normal) hemispheres were then collected. All tissues were immediately snap frozen in liquid nitrogen and stored at $-80^{\circ} \mathrm{C}$.

For real-time PCR, total RNA was extracted from peri-infarct cortex with TRIzol reagent (Roche) according to the manufacturer's instructions and the concentration was measured with NanoDrop 2000 spectrophotometer. A total of $2 \mu \mathrm{g}$ of total RNA was used to synthesize cDNA with a Transcriptor First Stand cDNA Synthesis Kit (Roche). Quantitative real-time PCR was performed with LightCycler 480 SYBR Green I Master Mix (Roche) using a LightCycler 480 real-time PCR system (Roche) according to the manufacturer's instructions. Primer pairs are listed in Table 2. The PCR conditions were as follows: initial denaturation at $95^{\circ} \mathrm{C}$ for $10 \mathrm{~min} 40$ cycles of $95^{\circ} \mathrm{C}$ for $10 \mathrm{~s}$ (denaturation), $60^{\circ} \mathrm{C}$ for $10 \mathrm{~s}$ (annealing), and $72^{\circ} \mathrm{C}$ for $20 \mathrm{~s}$ (extension). The relative mRNA expression levels were normalized to the reference gene GAPDH. All reactions were conducted in triplicate and the data were calculated using the $2^{-\Delta \Delta \mathrm{CT}}$ method.

For Western blotting, the peri-infarct tissues were lysed and the proteins were separated in SDS-PAGE gels and transferred onto PVDF membranes. The membranes were incubated in blocking buffer (TBST containing $5 \%$ skim milk powder) for $1 \mathrm{~h}$ at room temperature and immersed in primary antibodies overnight at $4^{\circ} \mathrm{C}$. Antibodies are listed in Table 3. After the membranes were washed, they were incubated with 
A

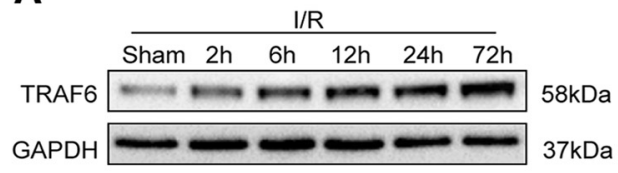

B

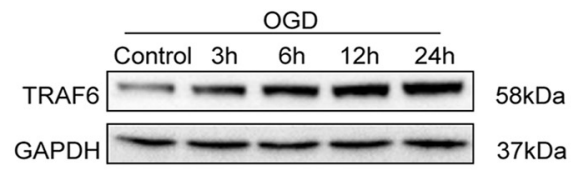

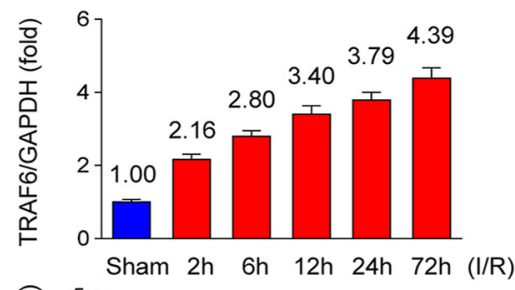

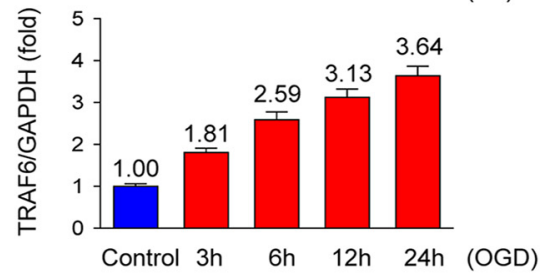

C
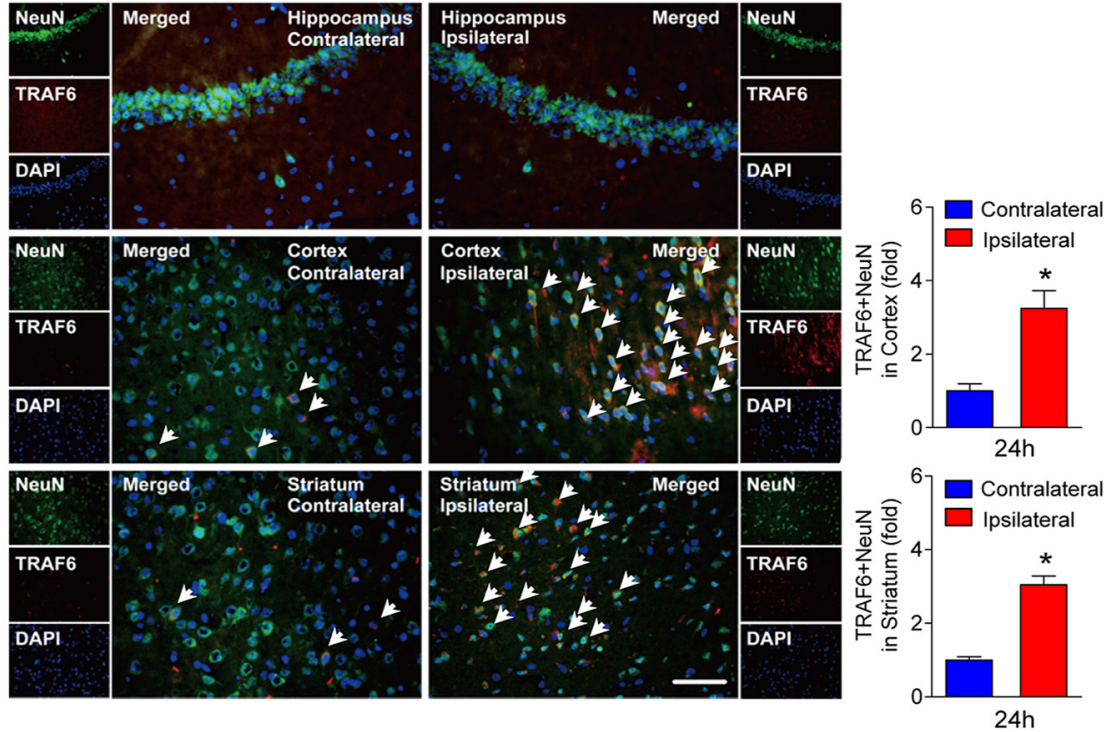

D

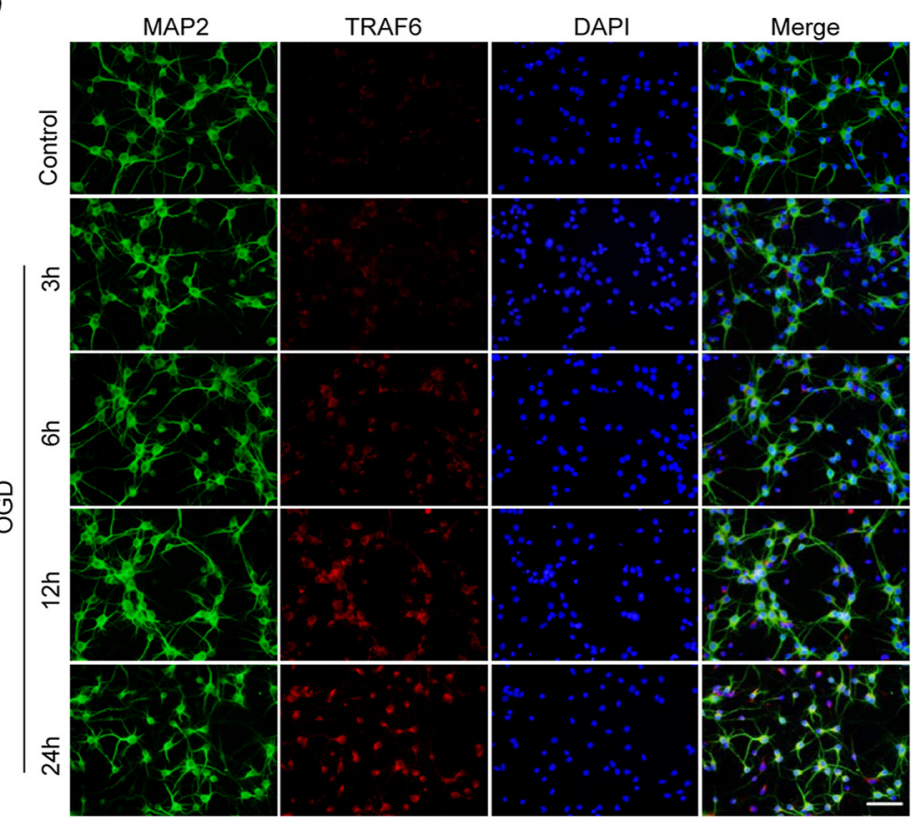

Figure 1. Expression of TRAF6 is elevated in cerebral experiencing I/R. Western blotting showed the expression of TRAF6 in vivo $(\boldsymbol{A})$ before and after $\mathrm{I} / \mathrm{R}$ and in vitro (B) after $0 \mathrm{GD} / \mathrm{reperfusion}$ at the indicated time points, $n=6$ per time point. $A, B, G A P D H$ served as a loading control for each time point. C, Mouse brains were stained for TRAF6 (red), NeuN (green), and DAPI (blue) in the hippocampus, cortex, and striatum from the ipsilateral ( $24 \mathrm{~h} \mathrm{I} / \mathrm{R}$ ) and contralateral sides (as labeled). White arrows indicate the TRAF6-positive neurons; Error bars indicate mean \pm SE. Scale bars, $50 \mu \mathrm{m}$. Right, Bar graph showing TRAF6 positive in the peri-infarct cortex and striatum (cortex, $n=6$ per group. ${ }^{*} p=0.0036$, two-tailed $t$ test; Striatum, $n=6$ per group. ${ }^{*} p=0.0002$, two-tailed $t$ test). D, Immunofluorescence staining of TRAF6 (red), MAP2 (green), and DAPI (blue) for primary cortical neurons subjected to $0 \mathrm{GD} /$ reperfusion for the indicated time points, $n=4$ per time point. Scale bar, $50 \mu \mathrm{m}$. 

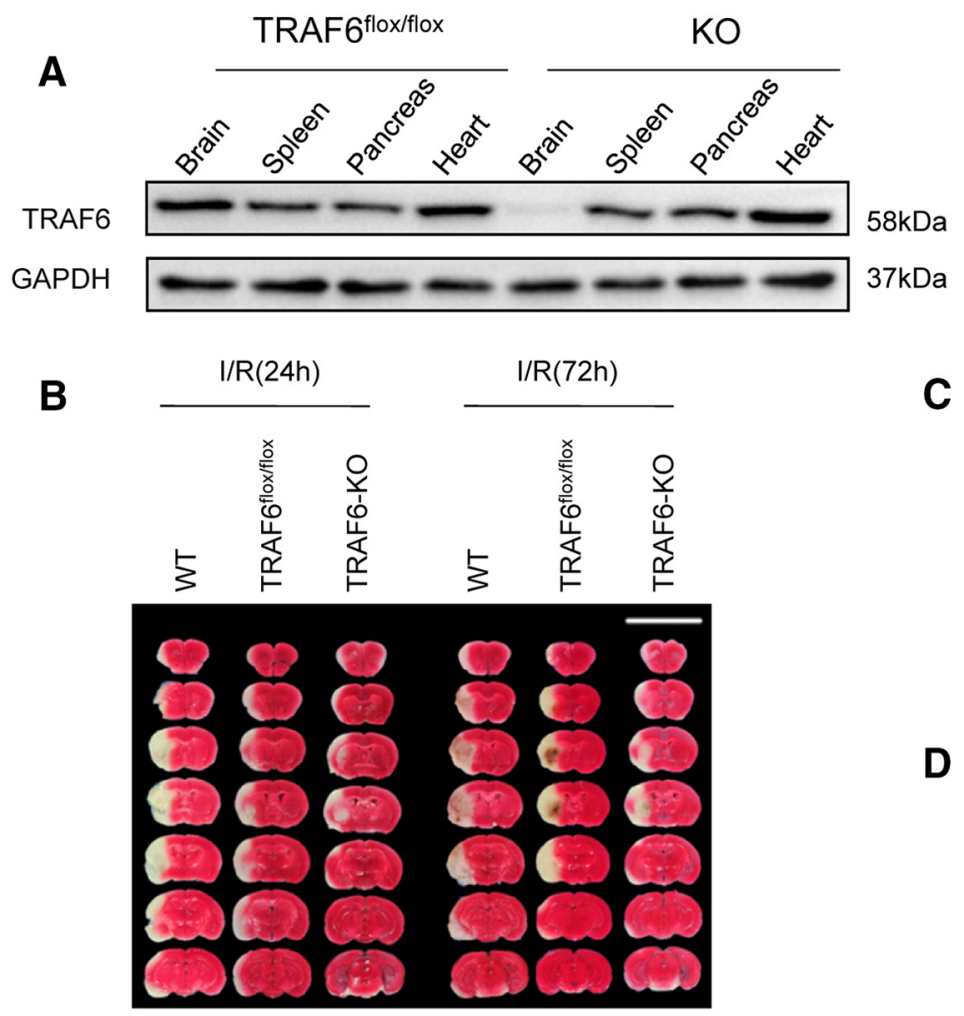

C
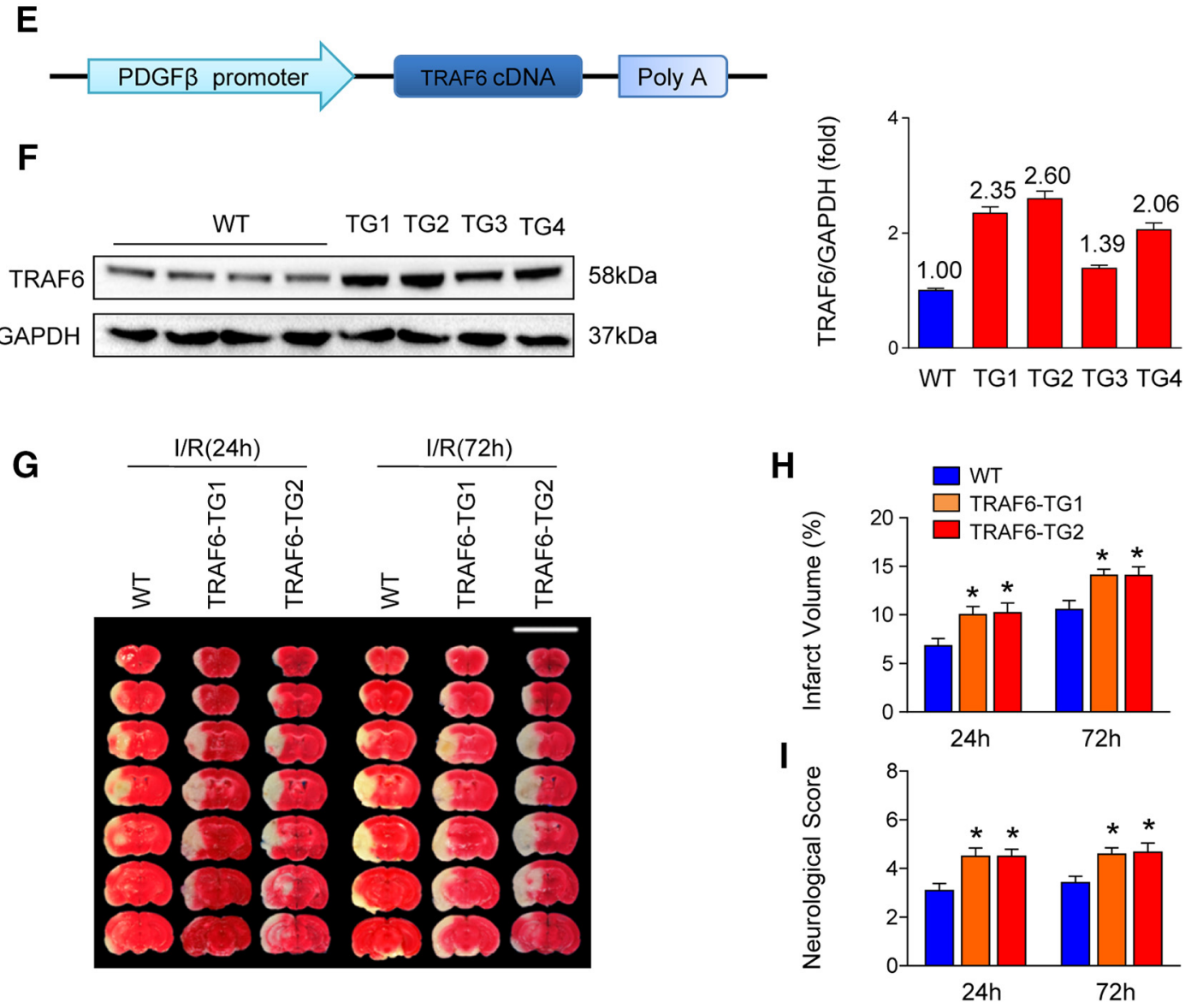

Figure 2. TRAF6 functions as a critical mediator of I/R injury. $A$, Expression of the TRAF6 from indicated tissues in the TRAF6 flox/flox and TRAF6-KO mice, $n=4$ per group. GAPDH served as the loading control. $\boldsymbol{B}$, TTC-stained sections from WT, TRAF ${ }^{\text {flox/flox }}$, and TRAF6-KO mice at 24 and $72 \mathrm{~h}$ after I/R. C, $\boldsymbol{D}$, Quantification of the infarct volumes $\left(n=12\right.$ per group, ANOVA, $F_{(2,32)}=21.900$ at $24 \mathrm{~h},{ }^{*} p<0.0001$ vs TRAF6 ${ }^{\text {flox/flox }} ; F_{(2,32)}=30.703$ at $72 \mathrm{~h},{ }^{*} p<0.0001$ vs TRAFf $\left.{ }^{\text {flox/flox }}\right)(C)$ and neurological deficit scores $(n=12$ per group, ANOVA, (Figure legend continues.) 
secondary antibodies. The protein bands were detected using a Bio-Rad imaging system and specific protein expression levels were normalized to GAPDH protein.

Cell culture and in vitro manipulation. Primary cortical neurons were isolated from the brains of 1-d-old Sprague Dawley rats. Briefly, the cortices were dissociated by incubating the brain tissue in $2 \mathrm{ml}$ of $0.125 \%$ trypsin (Invitrogen) for $15 \mathrm{~min}$ at $37^{\circ} \mathrm{C}$ and the trypsin was then inactivated by addition of $4 \mathrm{ml}$ of DMEM/F-12 (Invitrogen) containing 20\% fetal bovine serum (Invitrogen). After the cells were centrifuged for $5 \mathrm{~min}$ at $1000 \mathrm{rpm}$, the resulting pellet was resuspended in DMEM containing $20 \%$ fetal bovine serum. Sterile filters ( $200 \mu \mathrm{m}$ pore size) were used to filter neurons, which were then seeded on plates coated with poly-Llysine $(10 \mathrm{mg} / \mathrm{ml}$; Sigma-Aldrich). The neurons were cultured in Neurobasal medium (Invitrogen) supplemented with B27 (Invitrogen) and AraC (10 mm; Sigma-Aldrich) for $24 \mathrm{~h}$ at $37^{\circ} \mathrm{C}$ in an atmosphere containing $5 \% \mathrm{CO}_{2}$. Five days later, the neurons were subjected to transient oxygen and glucose deprivation (OGD) (serum-free glucose-free Locke's buffer, $\mathrm{pH} 7.2 ; 95 \% \mathrm{~N}_{2}$ and $5 \% \mathrm{CO}_{2}$ ) for $60 \mathrm{~min}$ and then returned to normal culture conditions for various times as indicated. The neurons cultured in normal levels of glucose in a humidified atmosphere containing $95 \%$ air and $5 \% \mathrm{CO}_{2}$ served as controls.

Recombinant adenoviral vectors. Adenoviruses containing sequences encoding rat TRAF6 (AdTRAF6), TRAF6 (C70A) (AdTRAF6-M), or short hairpin RNAs targeting TRAF6 (AdshTRAF6) were constructed for the in vitro studies. The cultured cortical neurons were infected for $24 \mathrm{~h}$ with adenovirus at a multiplicity of infection of 100 .

Cell viability. A nonradioactive cell counting kit-8 assay (CK04; Dojindo) was used to examine cell viability and was conducted according to the manufacturer's protocol. A commercially available colorimetric lactate dehydrogenase (LDH) cytotoxicity assay kit (G1782; Promega) was used to evaluate LDH release. Three independent experiments were performed.

GTP "charging" assay of endogenous and recombinant Rac1. HEK293T cells were transfected with the appropriate constructs. At $48 \mathrm{~h}$ after transfection, the cells were lysed in binding buffer ( $50 \mathrm{~mm}$ Tris- $\mathrm{HCl}, \mathrm{pH} 7.5$, $150 \mathrm{~mm} \mathrm{NaCl}, 1 \%$ Triton X-100, $10 \mathrm{mg} / \mathrm{ml}$ leupeptin, $10 \mathrm{~mm} \mathrm{NaF}, 2 \mathrm{~mm}$ $\mathrm{Na}_{3} \mathrm{VO}_{4}$, and $1 \mathrm{~mm}$ PMSF). GST-PAK1-CRIB (produced in the Escherichia coli system, $20 \mu \mathrm{g}$ ) preloaded onto GSH Sepharose was incubated for $2 \mathrm{~h}$ at $4^{\circ} \mathrm{C}$ with the precleared cell lysates or peri-infarct tissue lysates. After three washes with binding buffer, the amount of Rac-GTP bound to the beads was determined by SDS-PAGE, followed by immunoblot analysis of Flag or Racl.

Immunoprecipitation and GST pull-down assays. Cultured HEK293T cells were cotransfected with HA-Rac1, HA-Rac1 ${ }^{\text {T17N }}$ (i.e., Rac-GDP), or HA-Rac1 ${ }^{\text {G12V }}$ (i.e., Rac-GTP) and Flag-TRAF6 for $48 \mathrm{~h}$ and then the cell lysates were precleared and incubated with $1 \mu \mathrm{g}$ of antibody and $10 \mu \mathrm{l}$ of protein $\mathrm{A} / \mathrm{G}$-agarose beads on a shaker at $4^{\circ} \mathrm{C}$ overnight. The immunocomplex was collected, washed, and blotted using the indicated primary antibodies.

For the GST pull-down assay, HEK293T cells transfected with HisRacl or His-TRAF6 were lysed with his lysis buffer $(20 \mathrm{~mm}$ Tris- $\mathrm{HCl}, \mathrm{pH}$ 7.4, $150 \mathrm{~mm} \mathrm{NaCl}, 1 \%$ Triton X-100 containing protease inhibiter cocktail tablets (04693132001; zcomRoche). The cell lysis was then incubated with $20 \mu \mathrm{l}$ of Ni-NTA agarose (30210; Qiagen). Rosetta (DE3) E. coli was transformed with the vector pGEX-4T-1-GST-TRAF6 or pGEX-4T-1-

$\leftarrow$

(Figure legend continued.) $F_{(2,32)}=8.532$ at $24 \mathrm{~h},{ }^{*} p=0.005$ vs TRAF $6{ }^{\text {flox/flox }} ; F_{(2,32)}=21.770$ at $72 \mathrm{~h},{ }^{*} p=0.011$ vs TRAF6 ${ }^{\text {flox/flox }}(\boldsymbol{D})$ at 24 and $72 \mathrm{~h}$ after I/R. E, Schematic diagram showing the construction of the neuron-specific TRAF6-overexpressing mice. $\boldsymbol{F}$, Representative bands of TRAF6 from the founder WT and TG mouse lines, $n=4$ per group. GAPDH served as the loading control. G, TTC-stained sections from WT, TRAF6-TG1, and TRAF6-TG2 mice at 24 and $72 \mathrm{~h}$ after I/R. $\boldsymbol{H}, \boldsymbol{I}$, Quantification of the infarct volumes $\left(n=12\right.$ per group, ANOVA, $F_{(2,32)}=4.893$ at $24 \mathrm{~h}$, for TRAF6-TG1 ${ }^{*} p=0.0397$, for TRAF6-TG2, ${ }^{*} p=0.0259$ vs WT; $F_{(2,32)}=6.049$ at $72 \mathrm{~h}$, for TRAF6-TG1, ${ }^{*} p=0.0144$, for TRAF6-TG2, ${ }^{*} p=0.0153$ vs WT) $(\boldsymbol{H})$ and neurological deficit scores $\left(n=12\right.$ per group, ANOVA, $F_{(2,32)}=7.176$ at $24 \mathrm{~h}$, for TRAF6-TG1, ${ }^{*} p=0.0073$, for TRAF6-TG2, ${ }^{*} p=0.0073$ vs WT; $F_{(2,32)}=5.299$ at $72 \mathrm{~h}$, for TRAF6-TG1, ${ }^{*} p=0.0312$, for TRAF6-TG2, ${ }^{*} p=0.0192$ vs WT) $(I)$ at 24 and $72 \mathrm{~h}$ after l/R.
GST-Racl and induced with $0.1 \mathrm{~mm}$ isopropyl- $\beta$-D-thiogalactopyranoside when the E. coli reached an optical density at $600 \mathrm{~nm}$ of 0.8 . Afterward, the E. coli cells were lysed, and the extracts were incubated with glutathione Sepharose 4B beads (17075601; GE Healthcare Biosciences) for $4 \mathrm{~h}$ at $4^{\circ} \mathrm{C}$. The protein-loaded beads were washed 5 times with $1 \mathrm{ml}$ of PBS and incubated with immunopurified his-Racl or his-TRAF6 for an additional $4 \mathrm{~h}$ at $4^{\circ} \mathrm{C}$. The purified proteins were then washed 3 times with $1 \mathrm{ml}$ of His lysis buffer, boiled with $2 \times$ SDS loading buffer, resolved with SDS-PAGE, and analyzed with Western blotting using anti-his antibodies. A GST tag was used as the negative control under the same conditions.

In vivo ubiquitination assay. The in vivo ubiquitination assay was performed according to a previously described protocol (Ji et al., 2016). Briefly, cells were lysed in SDS lysis buffer (20 mM Tris-HCl, pH 7.4, 150 $\mathrm{mm} \mathrm{NaCl}, 1 \mathrm{~mm}$ EDTA, 1\% SDS) containing protease inhibitor cocktail tablets ( 04693132001 ; Roche) for $30 \mathrm{~min}$ at $4^{\circ} \mathrm{C}$ and denatured by heating for $5 \mathrm{~min}$. The lysates were diluted 10-fold with lysis buffer $(20 \mathrm{~mm}$ Tris- $\mathrm{HCl}, \mathrm{pH}$ 7.4, $150 \mathrm{~mm} \mathrm{NaCl}, 1 \mathrm{~mm}$ EDTA, 1\% Triton X-100) containing protease inhibitor cocktail tablets (04693132001; Roche). After the lysates were centrifuged at $12,000 \mathrm{rpm}$ for $10 \mathrm{~min}$ at $4^{\circ} \mathrm{C}$, the resulting supernatants were subjected to immunoprecipitation with the indicated antibodies.

In vitro ubiquitination assay. The tested proteins were expressed with a TNT Quick Coupled Transcription/Translation System Kit (L2080; Promega) according to the manufacturer's instructions. The synthesized proteins were then analyzed by SDS-PAGE. For the in vitro ubiquitination assay, $5 \mathrm{~nm}$ TRAF6 and $1 \mathrm{~mm}$ Racl protein were mixed with $100 \mathrm{~nm}$ His-E1, 1 mm His-E2 (Ubc13/Mms2) and $2.5 \mathrm{~mm}$ Bt-Ub in $50 \mathrm{~mm}$ ubiquitination reaction buffer from a ubiquitination kit (BML-UW99200001; Enzo Life Sciences) according to the manufacturer's instructions. The samples were subsequently separated via SDS-PAGE and detected with HRP-conjugated streptavidin (ab7403; Abcam).

Statistical analysis. The data are expressed as the means \pm SE. Data distribution was analyzed with the Kolmogorov-Smirnov or ShapiroWilk normality test. Comparisons among multiple groups were analyzed by using one-way ANOVA, followed by Bonferroni's post hoc test (equal variances assumed) or Tamhane's T2 post hoc test (equal variances not assumed). Comparisons between two groups were performed using an unpaired Student's $t$ test. For the nonparametric data, the Mann-Whitney test was applied. Statistical significance was set as $p<0.05$. The sample size was predetermined by analyzing pre-experimental data with PASS (power analysis and sample size) software. For animal studies, the sample size was predetermined by our prior experiment. All in vivo and imaging studies were performed in a blinded manner.

\section{Results}

\section{TRAF6 expression is increased in ischemic cerebral tissue}

The expression of TRAF6 after ischemic stroke was examined to investigate its response during ischemic stroke. We found that TRAF6 expression was increased in brain homogenates in a timedependent manner. Its expression was induced as early as $2 \mathrm{~h}$ after MCAO and increased to 4.39-fold of its baseline level at $72 \mathrm{~h}$ after MCAO (Fig. 1A). A similar expression pattern was observed in OGD-challenged primary cortical neurons isolated from rats (Fig. $1 B$ ). MCAO/reperfusion-induced cerebral lesions were observed in cortical and striatal neurons but not in hippocampal neurons (Fig. 1C), where blood flow was preserved (Engel et al., 2011). Further immunofluorescence staining of TRAF6 and the neuronal marker NeuN in different regions of the brain indicated that TRAF6 was expressed in hippocampal, cortical, and striatal neurons at baseline and was upregulated only in the cortex and striatum (sites of interrupted blood flow), not in the hippocampal neurons after MCAO/reperfusion (Fig. 1C). Consistent with these results, immunofluorescence staining of TRAF6 and MAP2 in the primary cortical neurons also revealed the time-dependent manner of OGD-induced TRAF6 expression (Fig. 1D). These 
A

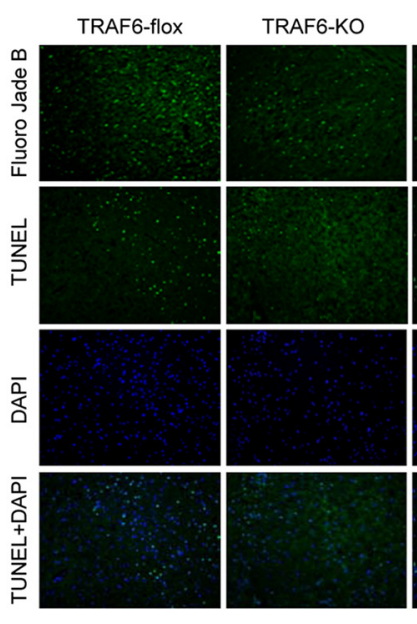

D

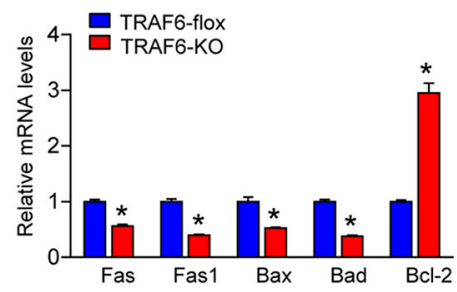

E

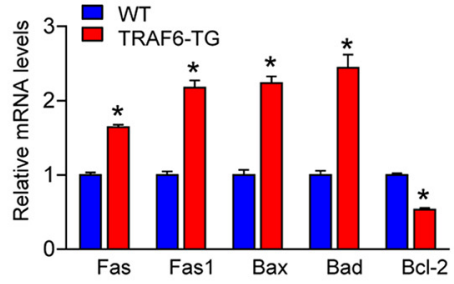

B
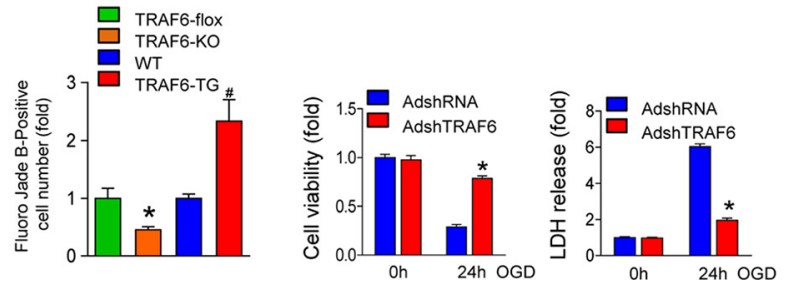

C

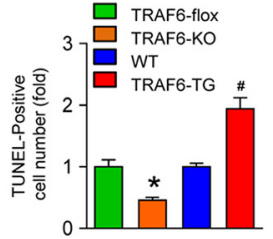

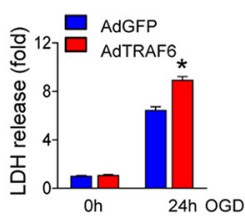

Oh $\quad 24 \mathrm{~h} \mathrm{OGD}$

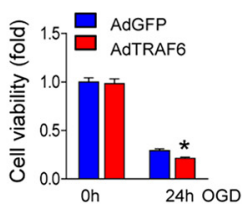

$\mathbf{F}$
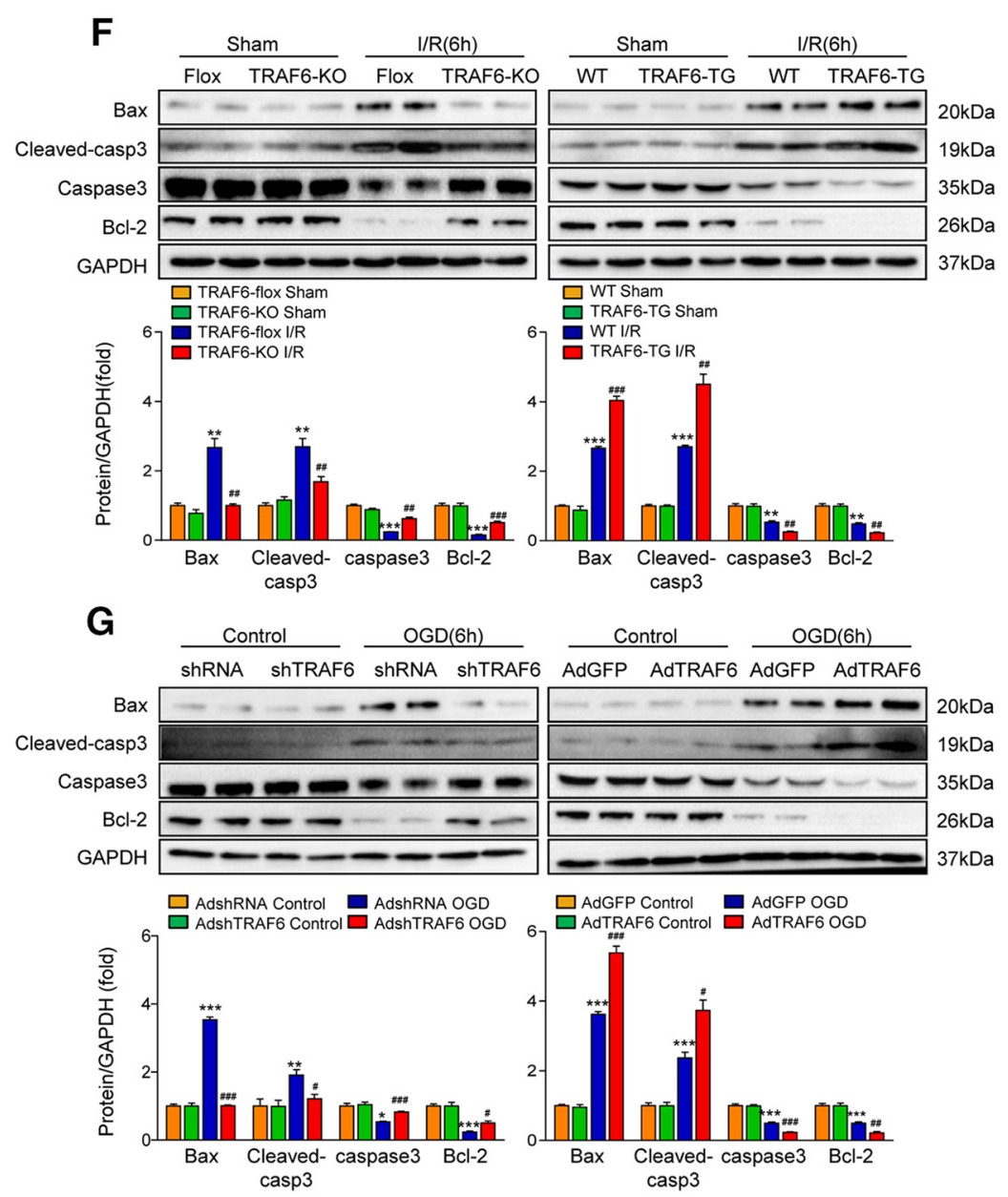

Figure 3. TRAF6 exacerbates I/R-induced neuronal death. $A$, Fluoro Jade $B$ and TUNEL staining in brain sections were performed at $24 \mathrm{~h}$ after $I / R$. DAPI was used to stain the nuclei. Scale bars, $50 \mu \mathrm{m}$. Right, Quantification of Fluoro Jade B-positive cell (top right, $n=4-5$ per group, for TRAF6-K0, $F_{(1,6)}=8.391,{ }^{*} p=0.0209$ vs TRAF6-flox; for TRAF6-TG, $F_{(1,7)}=3.371, \# p=0.0143$ vs WT, Mann-Whitney test) and TUNEL-positive cell (bottom right, $n=4-6$ per group, for TRAF6-K0, $F_{(1,8)}=2.413,{ }^{*} p=0.0008$ vs TRAF6-flox; for TRAF6-TG, $F_{(1,7)}=4.997$, \#p $=0.0050$ vs WT two-tailed $t$ test). $B, C$, Cell viability (left) and LDH release (right) were assessed and quantified $24 \mathrm{~h}$ after $0 \mathrm{GD} /$ reperfusion stimulation. Primary neurons were infected AdshTRAF6 $(n=9 \mathrm{per}$ group, for cell viability, $F_{(3,32)}=0.063,{ }^{*} p<0.0001$ vs AdshRNA; for LDH release, $F_{(3,32)}=1.054, \# p<0.0001$ vs AdshRNA two-tailed $t$ test) $(\boldsymbol{B})$, AdTRAF6 ( $n=9$ per group, for cell viability, $F_{(3,32)}=$ $0.429,{ }^{*} p=0.0021$ vs AdGFP; for LDH release, $F_{(3,32)}=0.022,{ }^{*} p<0.0001$ vs AdGFP two-tailed $t$ test) $(\boldsymbol{C})$, or control adenoviruses. $\boldsymbol{D}, \boldsymbol{E}$, Real-time PCR showing the mRNA expression of the indicated genes from TRAF6-KO ( $n=4$ per group, for Fas, ${ }^{*} p<0.0001$ vs TRAF6-flox, Mann-Whitney test; for Fasl, Bax, Bad, Bcl2, ${ }^{*} p<0.0001$, for Bax2, ${ }^{*} p=0.0002$ vs TRAF6-flox two-tailed $t$ test) (D) and TRAF6-TG ( $n=4$ per group, for Fas, Fasl, ${ }^{*} p<0.0001$ vs TRAF6-flox, two-tailed $t$ test; for Bax, Bad, Bcl2, ${ }^{*} p<0.0001$ vs WT, Mann-Whitney test) (E) mice brains in response to cerebral I/R injury. $\boldsymbol{F}$, Western blot analysis (top) and relative quantification (bottom) of the apoptotic related proteins in the brain from sham- and MCA0-operated TRAF6-KO (left) and TRAF6-TG (right) mice. GAPDH is served as loading control $\left[n=6\right.$ per group, ANOVA, ${ }^{* *} p<0.01,{ }^{* * *} p<0.001$ vs sham; \#\#p $<0.01$, \#\#\#p $<0.001$ vs TRAF $6{ }^{\text {flox/flox }}$ mice (left) or $n=6$ per group, ANOVA, ${ }^{* *} p<0.01$, ${ }^{* * *} p<0.001$ vs sham; \#\#p $<0.01$, \#\#\#p $<0.001$ vs WT mice (right)]. G, Western blot analysis (top) and relative quantification (bottom) of the apoptotic related proteins in cell lysates from AdshTRAF6- or AdTRAF6-infected primary neurons. GAPDH served as loading control $\left[n=4\right.$ per group, ANOVA, ${ }^{* *} p<0.01,{ }^{* * *} p<0.001$ vs control; \#p $<0.05$, \#\#p $<0.01$, \#\#\#p $<0.001$ vs AdshRNA (left) or $n=4$ per group, ANOVA, ${ }^{*} p<0.05,{ }^{* *} p<0.01,{ }^{* * *} p<0.001$ vs control; $\# p<0.05$, \#\#p $<0.01$, \#\#\# $<0.001$ vs AdGFP (right)]. Error bars indicate mean \pm SE. 
A

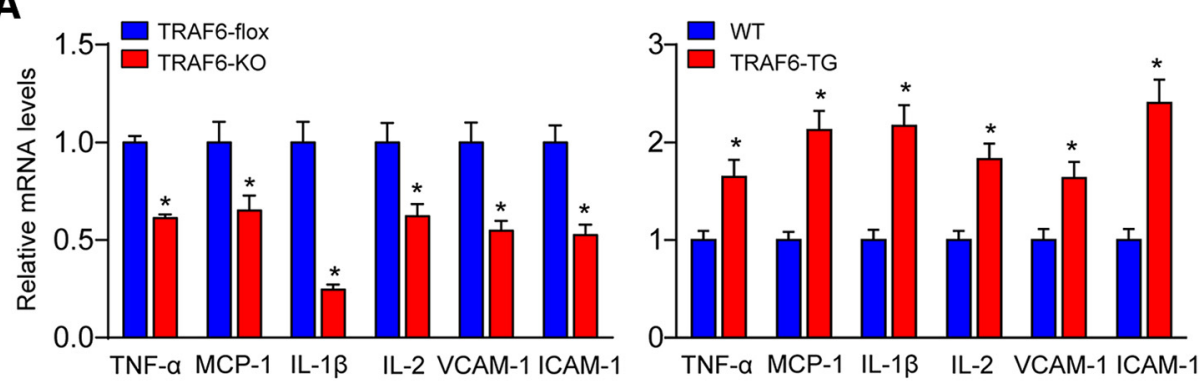

B
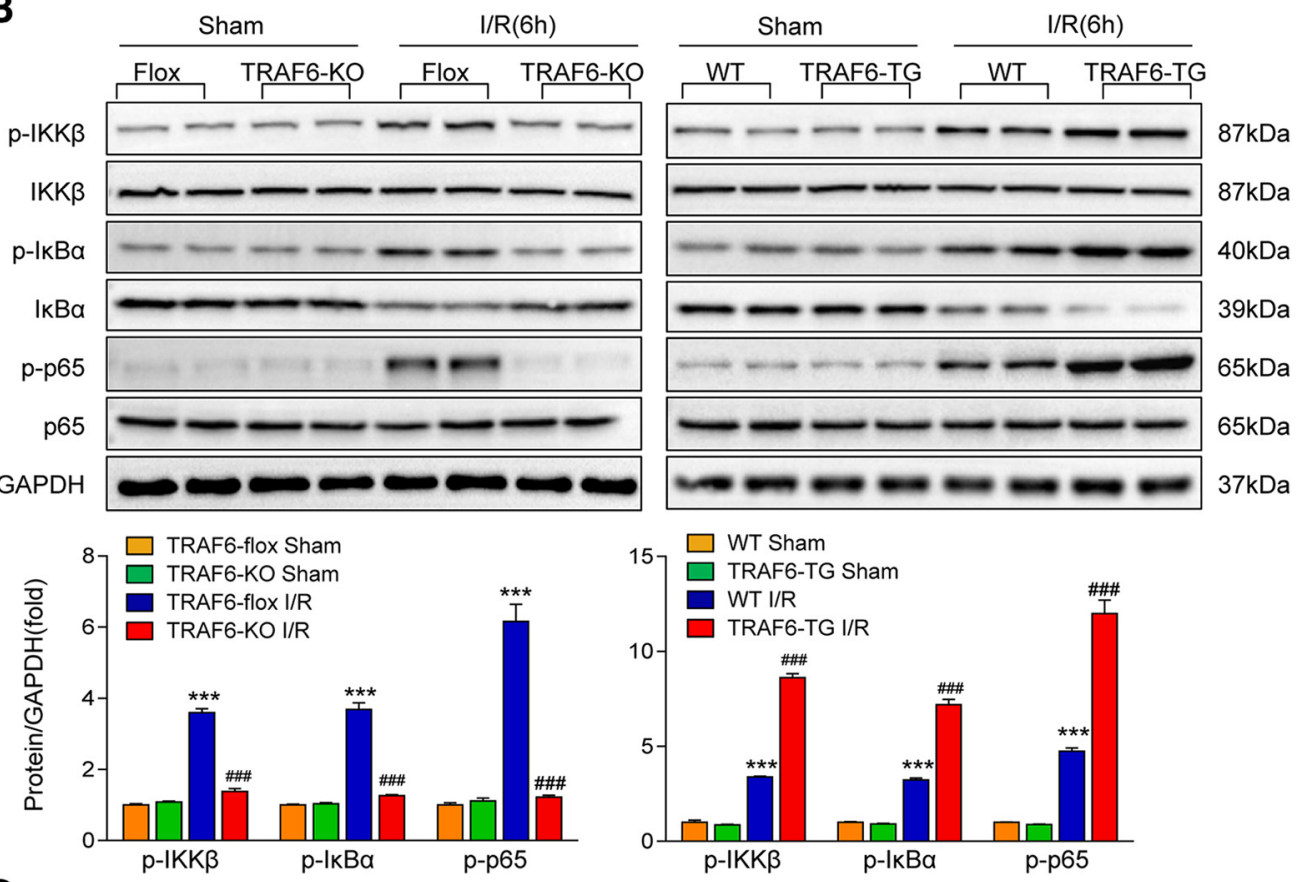

C

Control

OGD(6h)

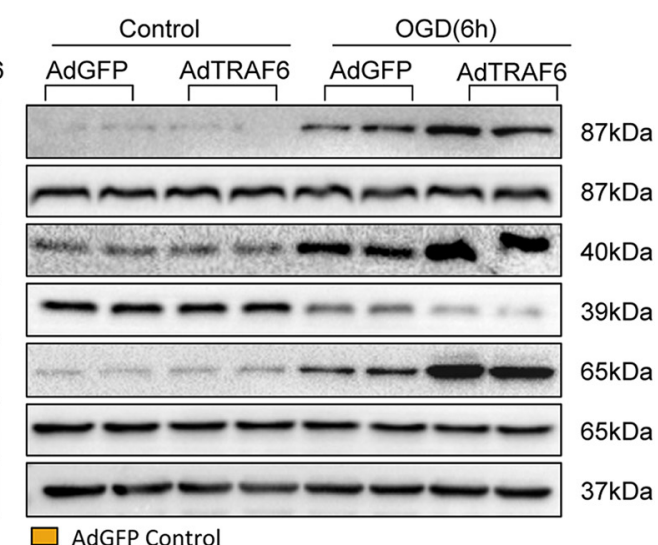

GAPDH

AdshRNA AdshTRAF6 AdshRNA AdshTRAF6

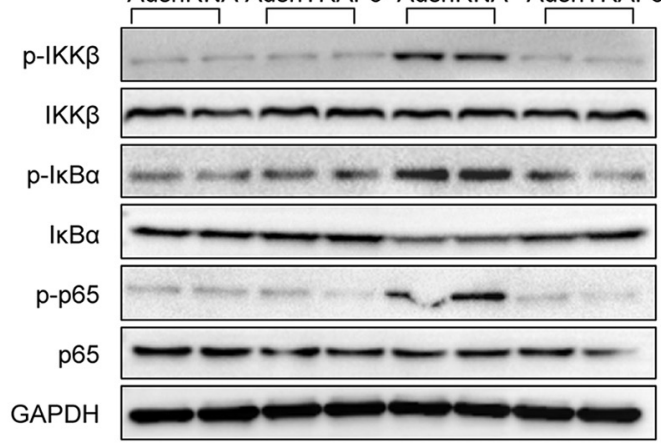

$\square$ AdshRNA Control

$\square$ AdshTRAF6 Contro

- AdshRNA OGD

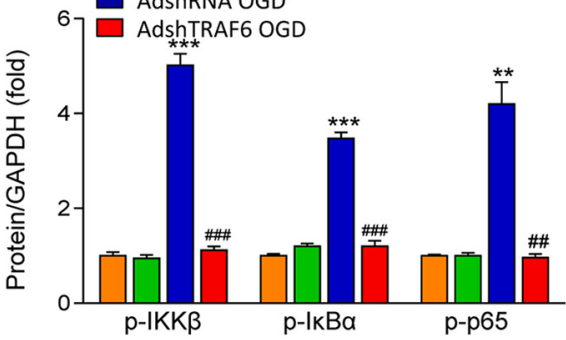
$\square$ AdGFP Control
$\square$ AdTRAF6 Control
adGFP OGD

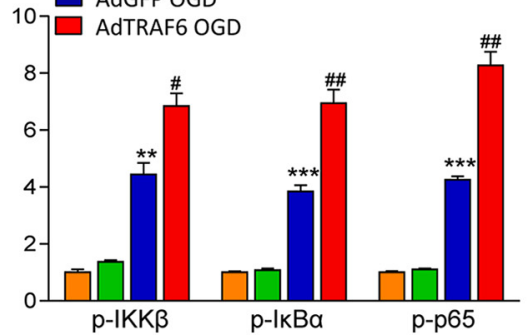

Figure 4. The cerebral I/R-induced inflammatory response is significantly aggravated by TRAF6. A, Relative mRNA levels of the proinflammatory genes in I/R-injured brain in TRAF6-K0 and TRAF6-TG mice, TRAF6 ${ }^{\text {flox/flox }}$, and WT mice served as control, respectively. The results were normalized to GAPDH $\left[n=4\right.$ per group, for TNF- $\alpha,{ }^{*} p<0.0001$, for MCP- $1 p=0.0351$, for IL- $1 \beta p=$ 0.0043 , for IL-2 $p=0.0174$, for VCAM1 $p=0.0073$, for ICAM-1 $p=0.0036$ vs TRAF6-flox, two-tailed $t$ test (left); for TNF- $\alpha,{ }^{*} p=0.0171$, for MCP-1 (Figure legend continues.) 
A

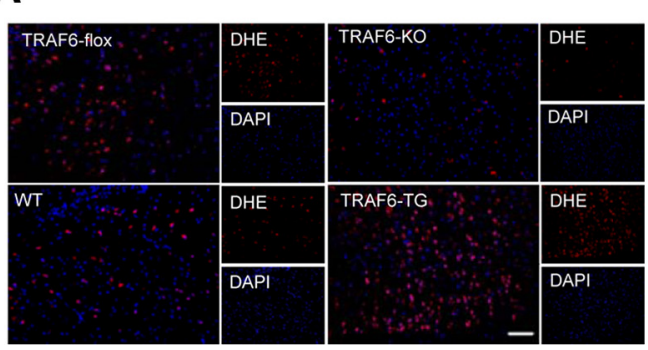

B
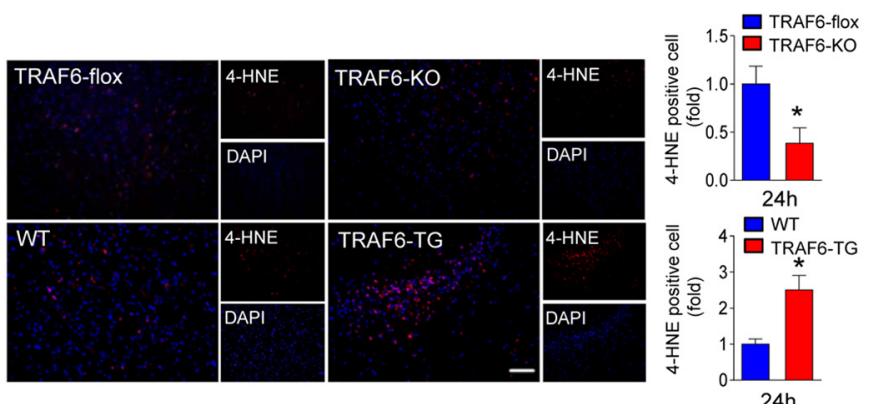

C

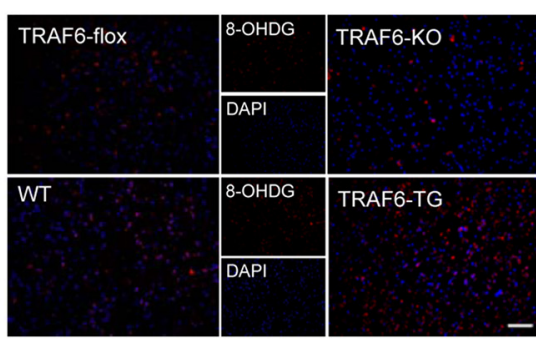

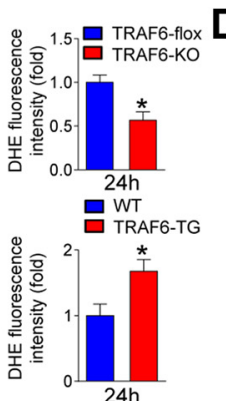
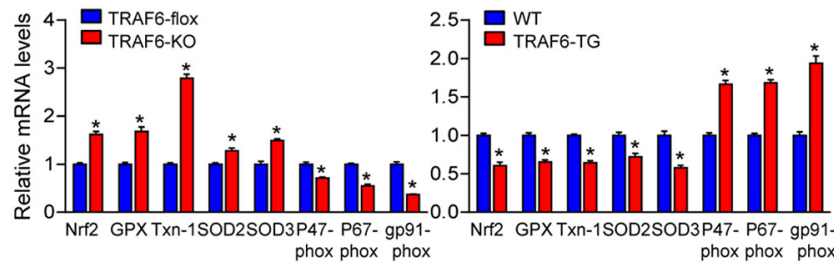

$\mathbf{E}$
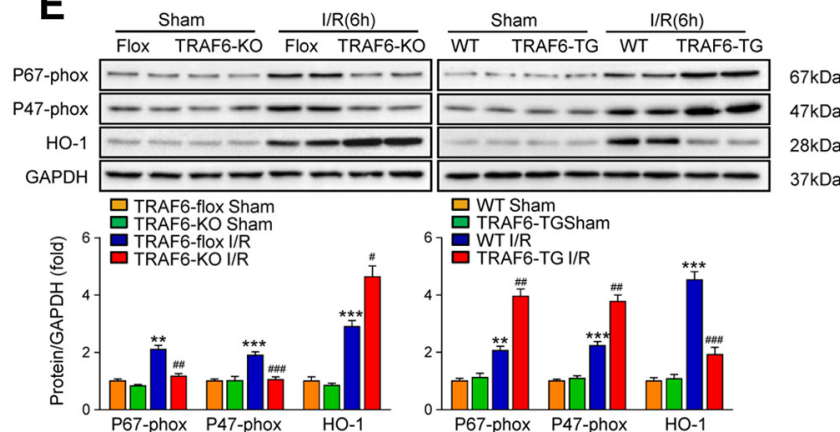

$\mathbf{F}$

Comtrol

OGD(6h)

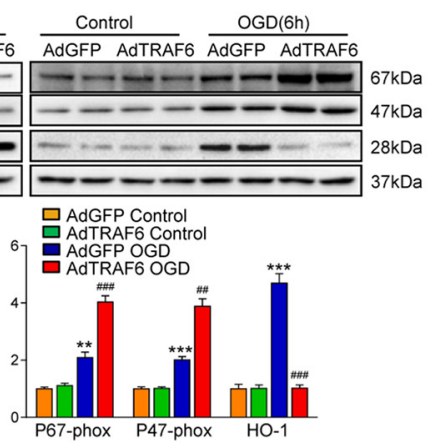

Figure 5. TRAF6 enhances $1 / R$-induced oxidative stress. $\boldsymbol{A}-\boldsymbol{C}$, Representative images of the cortices from the indicated mouse lines stained with DHE $(\boldsymbol{A})$, 4-HNE $(\boldsymbol{B})$, and 8-0HDG $(\boldsymbol{C})$ after I/R; DAPI indicates the nuclei. Merged images are shown. Relative quantification of neurons positive for the target proteins is shown $\left[n=3-5\right.$ per group for TRAF6-K0, $F_{(1,7)}=$ $0.893,{ }^{*} p=0.0128$ vs TRAF6-flox; for TRAF6-TG, $F_{(1,6)}=0.532, \# p=0.0491$ vs WT, two-tailed $t$ test $(\boldsymbol{A}) ; n=3-5$ per group, for TRAF6-K0, $F_{(1,7)}=0.122,{ }^{*} p=0.0397$ vs TRAF6-flox; for TRAF6-TG, $F_{(1,7)}=3.511$, \#p $=0.0157$ vs WT, two-tailed $t$ test $(\boldsymbol{B}) ; n=3-5$ per group, for TRAF6-K0, $F_{(1,7)}=6.966,{ }^{*} p=0.1067$ vs TRAF6-flox; for TRAF6-TG, $F_{(1,6)}=10.424, \# p=$ 0.0032 vs WT, two-tailed $t$ test $(\boldsymbol{C})$ ]. D, Relative mRNA levels of the oxidative stress related genes in I/R-injured brain in TRAF6-K0 and TRAF6-TG mice, TRAF6 ${ }^{\text {flox/flox }}$, and WT mice served as control, respectively. The results were normalized to GAPDH $\left[n=4\right.$ per group, for Nrf2, GPX, Tnx-1, phox67, gp91, ${ }^{*} p<0.0001$, for S0D2, ${ }^{*} p=0.0020$ vs TRAF6-flox, two-tailed $t$ test; for S0D3, ${ }^{*} p<0.0001$, for phox47, ${ }^{*} p=0.0002$ vs TRAF6-flox, Mann-Whitney test (left); for Tnx-1, ${ }^{*} p<0.0001$ vs TRAF6-flox, two-tailed $t$ test; for Nrf2, GPX, SOD3, phox47, phox67, gp91, ${ }^{*} p<0.0001$, for S0D2, ${ }^{*} p=0.0003$ vs WT, Mann-Whitney test (right)]. $E$, $\boldsymbol{F}$, Western blotting and quantification of the indicated proteins from mice and cells lacking or overexpressing TRAF6 were evaluated in vivo $(\boldsymbol{E})$ and in vitro $(\boldsymbol{F})$, respectively. GAPDH served as the loading control $\left[n=6\right.$ per group, ANOVA, ${ }^{* *} p<0.01,{ }^{* * *} p<0.001$ vs sham; \#p $<$ 0.05 , \#\#p $<0.01$, \#\#\#p $<0.001$ vs TRAF6 ${ }^{\text {flox/flox }}$ mice (left) or WT mice (right) (E); $n=4$ per group, ANOVA, ${ }^{* *} p<0.01,{ }^{* * *} p<0.001$ vs sham; \#p $<0.05$, \#\#p $<0.01$, \#\#\#p<0.001 vs control (left) or AdGFP (right) (F)].

(Figure legend continued.) $p=0.0058$, for IL-1 $\beta p=0.0056$, for IL-2 $p=0.0041$, for VCAM1 $p=0.0179$, for ICAM- $1 p=0.0020$ vs WT, two-tailed $t$ test (right)]. $\boldsymbol{B}$, Immunoblot analysis (top) and relative quantification (bottom) of the NF- $\kappa B$ cascade in brain from sham- and MCAOoperated TRAF6-KO (left) and TRAF6-TG (right) mice. GAPDH served as loading control $[n=6$ per group, ANOVA, ${ }^{* *} p<0.01,{ }^{* * *} p<0.001$ vs sham; \#\#p $<0.01$, \#\#\#p $<0.001$ vs TRAF6 ${ }^{\text {flox/flox }}$ mice (left) or $n=6$ per group, ANOVA, ${ }^{* * *} p<0.001$ vs sham; \#\# $<0.01$, $\# \#$ \# $<0.001$ vs WT mice (right)]. C, Immunoblot analysis (top) and relative quantification (bottom) of the NF- $\kappa B$ cascade in neurons subject $0 G$ /reperfusion infected with AdshTRAF6(left) or AdTRAF6 (right). GAPDH served as loading control $\left[n=4\right.$ per group, ANOVA, ${ }^{* *} p<$ 0.01 , ${ }^{* * *} p<0.001$ vs control; \#\# $<0.01$, \#\#\#p $<0.001$ vs AdshRNA (left) or $n=6$ per group, ANOVA, ${ }^{* *} p<0.01,{ }^{* * *} p<0.001$ vs control; $\# p<0.05$, \#\#p $<0.01$ vs AdGFP (right)]. Error bars indicate mean $\pm \mathrm{SE}$. data suggested that TRAF6 may have a critical role in neurons during the progression of ischemic stroke.

\section{TRAF6 exacerbates poststroke cerebral injury}

To explore the function of TRAF6 in ischemic stroke, conditional TRAF6-knock-out mice were generated using the Cre/loxP system (hereafter referred to as TRAF6-KO mice) and the genotype was validated by immunoblotting (Fig. $2 A$ ). We found that the infarct size in the TRAF6-KO mice was significantly smaller at 24 and $72 \mathrm{~h}$ after I/R injury compared with both the WT and TRAF6 ${ }^{\text {flox/flox }}$ mice (Fig. $2 B, C$ ). Neurological deficits were also decreased in the TRAF6-KO mice at both time points (Fig. 2D). Therefore, we speculated that TRAF6 ablation might be beneficial for ischemic stroke outcomes. To verify this possibility, we 
A
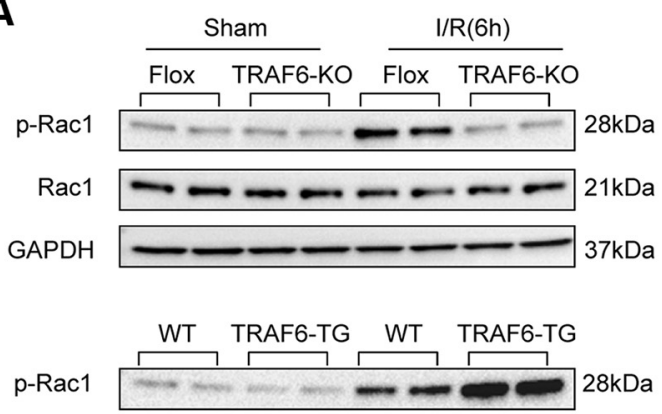

$\operatorname{Rac1}=-\infty-\infty 21 \mathrm{kDa}$
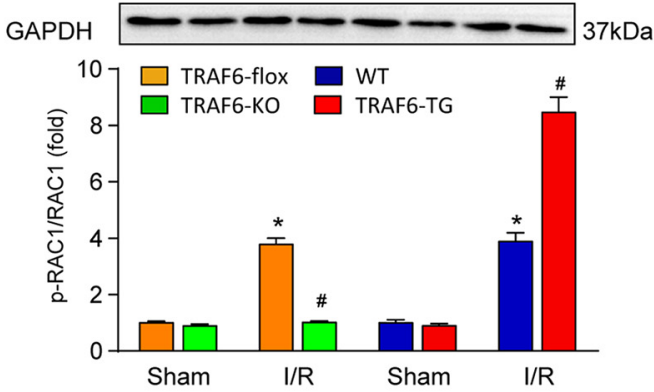

C

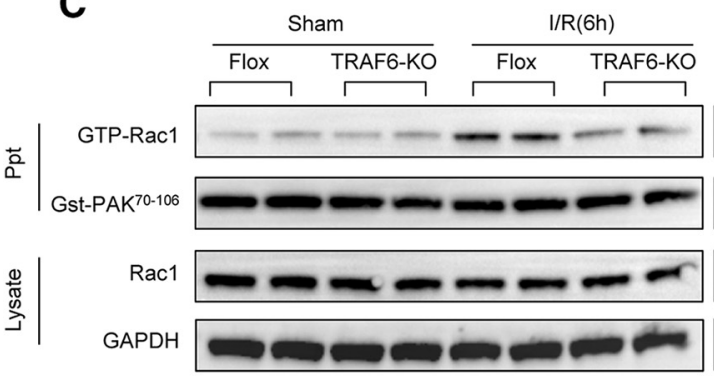

D

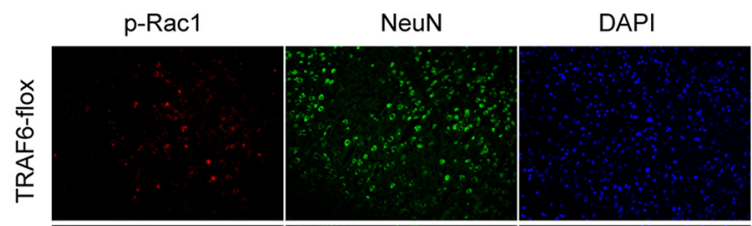

○

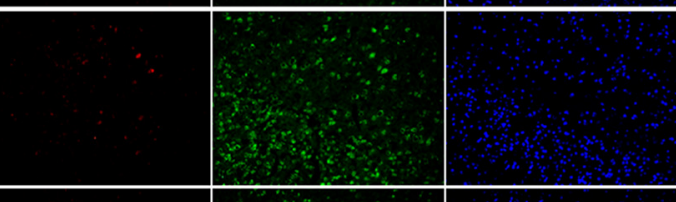

5

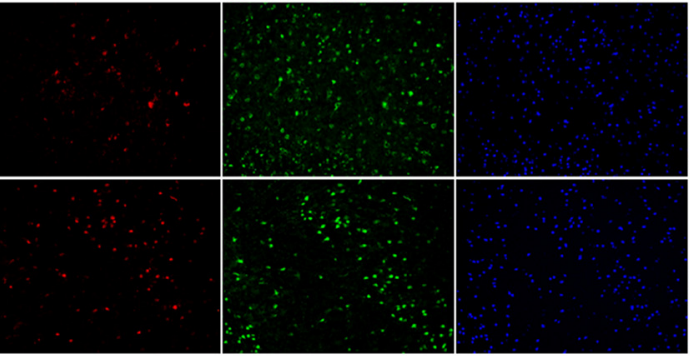

B

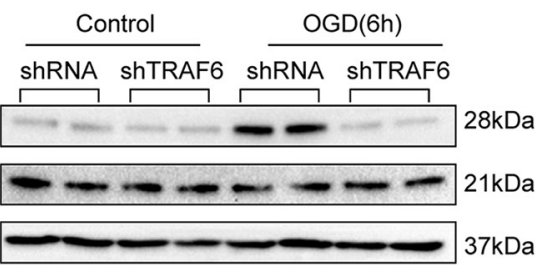

AdGFP AdTRAF6 AdGFP AdTRAF6
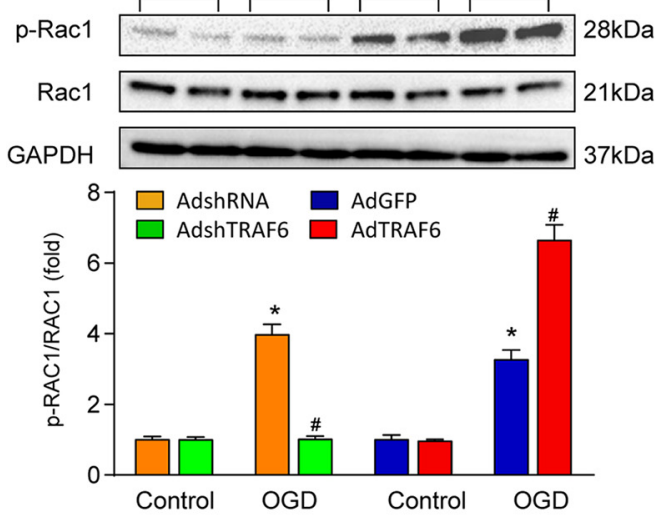
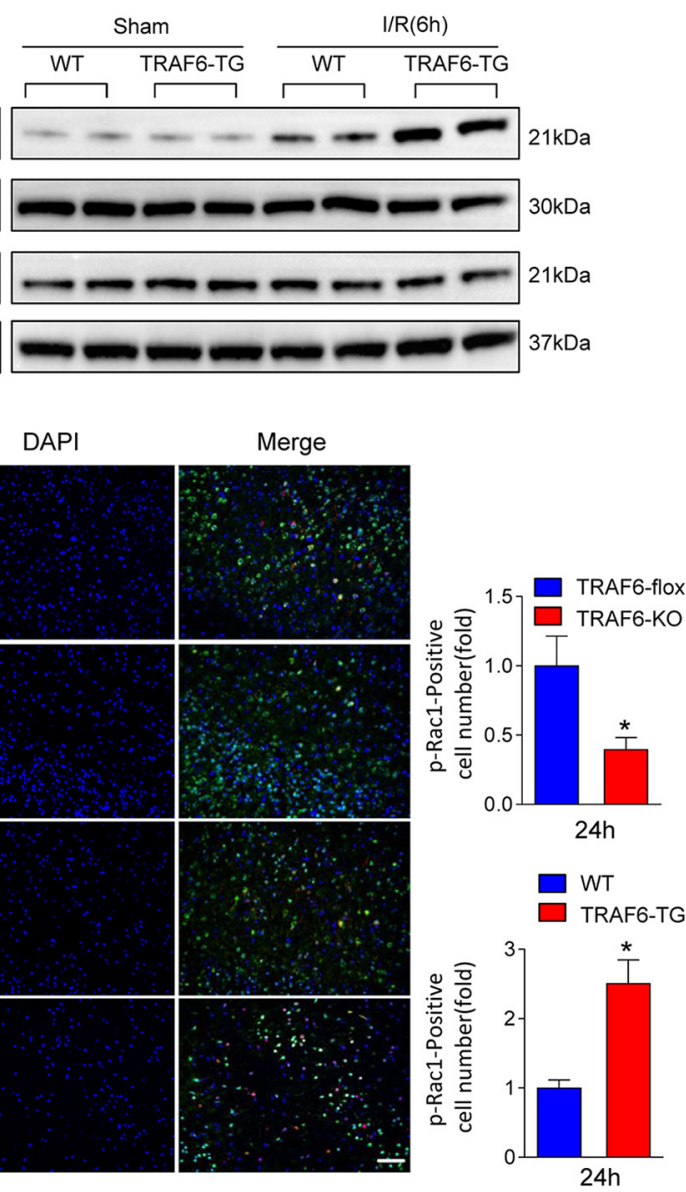

Figure 6. Cerebral I/R induced Rac-1 activation was enhanced by TRAF6. $A, B$, Western blots of the expression of total and phosphorylated Rac- 1 in I/R-injured mice $(\boldsymbol{A})$ and $0 G D-$ treated primary neurons (B). GAPDH served as loading control $\left[n=6\right.$ per group, ANOVA, for TRAF6-KO, $F_{(3,20)}=132.273,{ }^{*} p=0.0002$ vs sham, $\# p=0.0002$ vs TRAF6 floxfllox (left); for TRAF6-TG, $F_{(3,20)}=121.992$, ${ }^{*} p=0.0006$ vs sham, $\# p=0.0006$ vs WT (right) $(A) ; n=4$ per group, ANOVA, for AdshTRAF6, $F_{(3,12)}=77.706,{ }^{*} p=0.0005$ vs control, $\# p=0.0005$ vs AdshRNA (left); for AdTRAF6, $F_{(3,12)}=$ $96.261,{ }^{*} p=0.0008$ vs control, $\# p=0.0010$ vs AdGFP (right)]. B, C, Precipitation (Ppt) by GST-PAK70-106 (GST-PAK) of active (GTP-bound) Rac1 in cortex from sham- and MCA0-operated TRAF6-K0 (left), TRAF6-TG (TG; right) mice, and relative control. Bottom, Immunoblot analysis of PAK and total Rac1 in the cortex; GAPDH served as loading control ( $n=3-4$ per group). D, Immunofluorescence staining for p-Rac1 (red), NeuN (green), and DAPI (blue) was performed in brain sections of the indicated mice. Right, Quantification of the p-Rac1-positive neuron numbers $\left[n=3-5\right.$ per group, for TRAF6-K0, $F_{(1,7)}=2.211,{ }^{*} p=0.0252$ vs TRAF6-flox (top); for TRAF6-TG, $F_{(1,6)}=2.710$, $\# p=0.0022$ vs WT, two-tailed $t$ test]. Error bars indicate mean \pm SE. 
A

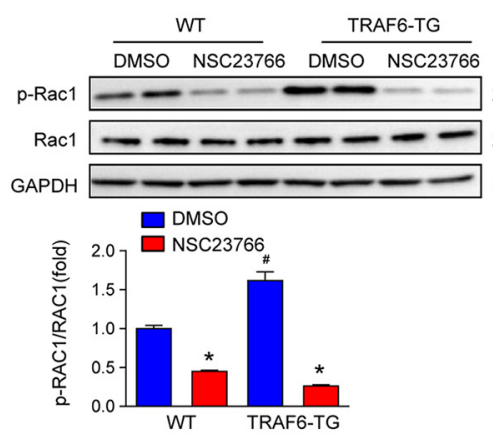

B

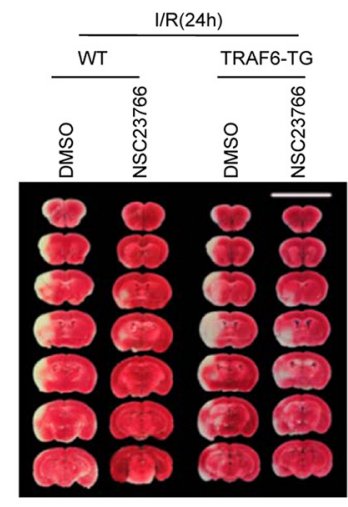

C

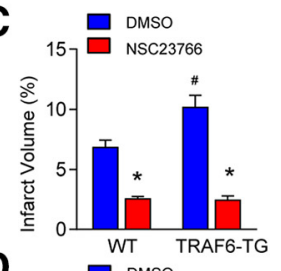

D

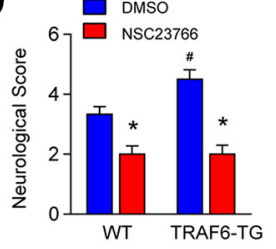

E
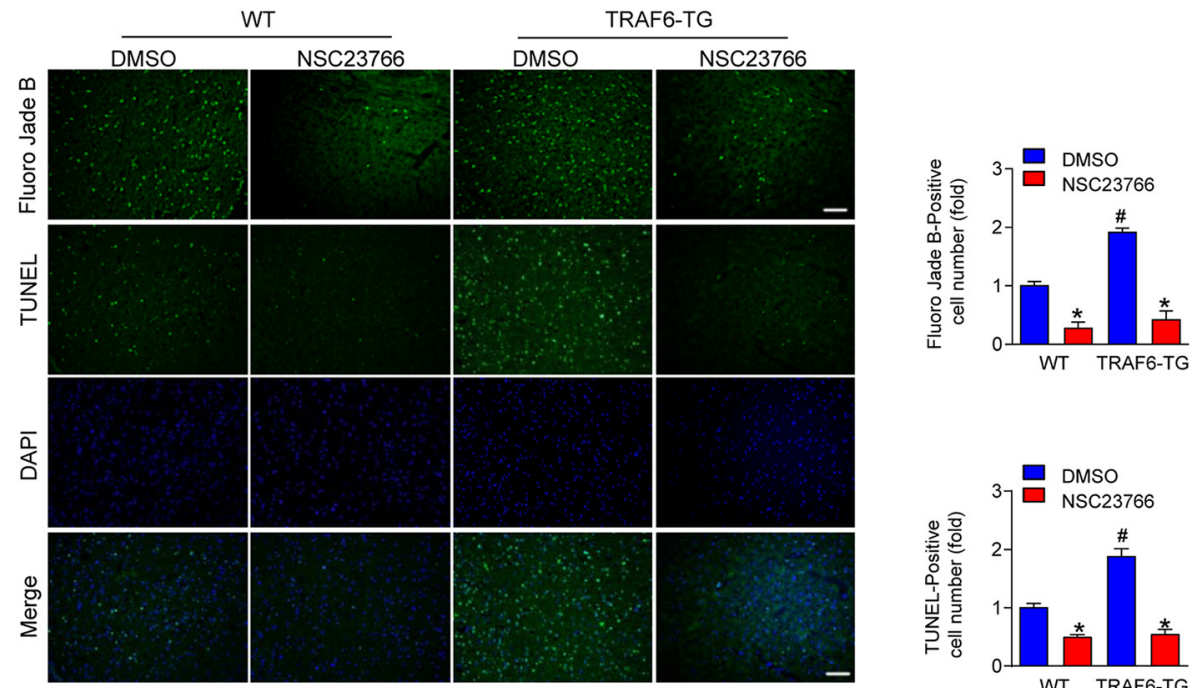

$\mathbf{F}$

$\square$ WT DMSO
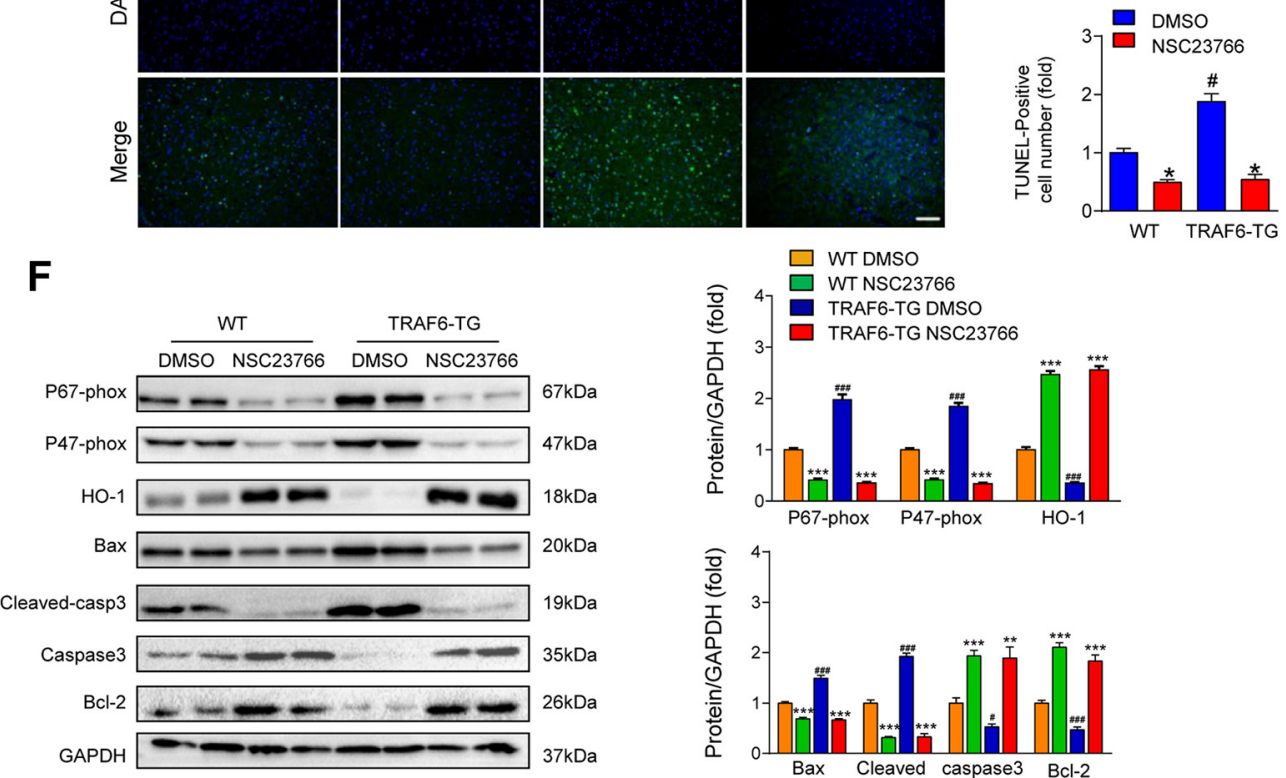

G
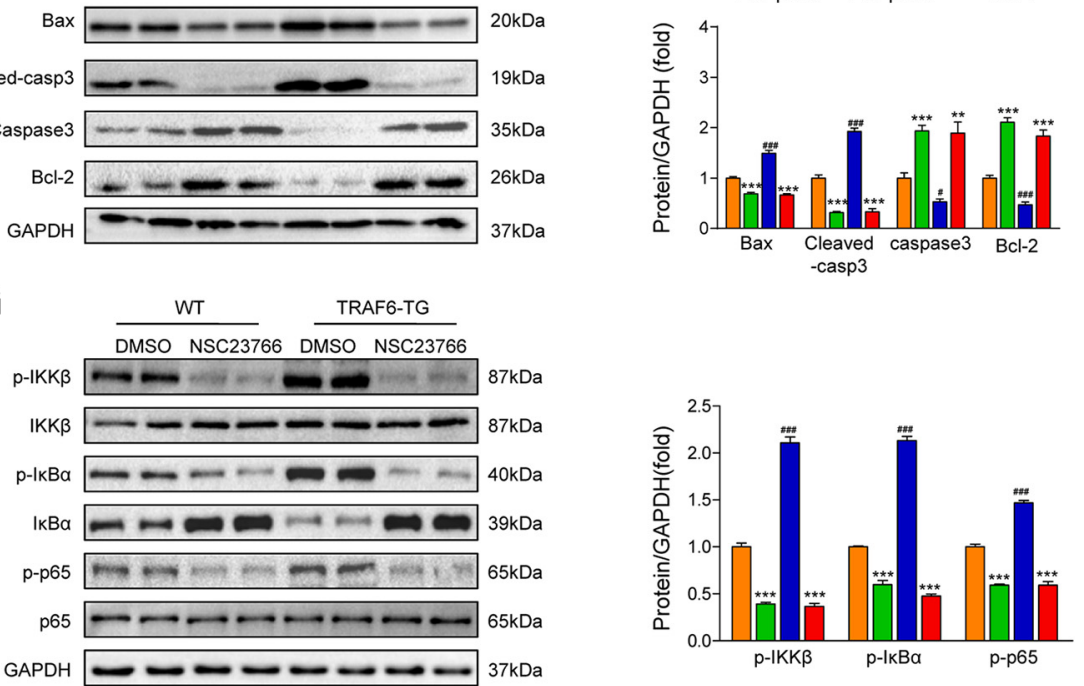

Figure 7. Inhibition of Rac1 abolishes the procerebral injury effect of TRAF6 overexpression in ischemic stroke. $A$, Western blot analysis (left) and relative quantification (right) of the levels of total and phosphorylated Rac1 in brain from the TG mice treated with NSC23766 and DMSO (control). GAPDH served as loading control ( $n=4$ per group, ANOVA, $F_{(3,12)}=99.103$, for WT $* p=0.0001$ vs DMS0, for TRAF6-TG, ${ }^{*} p=0.0003$ vs DMS0, $\# p=0.0108$ vs WT). $\boldsymbol{B}-\boldsymbol{E}$, TRAF6-induced neuronal damage was dependent on Rac1. $\boldsymbol{B}$, TTC-stained sections from WT and TRAF6-TG mice treated with NSC23766 and DMSO, respectively. Quantification of infarct volumes $\left[n=12\right.$ per group, ANOVA, $F_{(3,44)}=34.878$, for WT ${ }^{*} p=0.0006$ vs DMSO, (Figure legend continues.) 
generated four conditional TRAF6-overexpressing transgenic mouse lines using the PDGF- $\beta$ promoter upstream of TRAF6, which results in neuron-specific overexpression (Fig. $2 E$ ). Immunoblots demonstrated that cerebral TRAF6 expression in the transgenic mice was higher than that in the WT mice (Fig. $2 F$ ). Two transgenic mouse lines (TRAF6-TG1 and TRAF6-TG2) were used for further experiments. Compared with the WT mice, the TRAF6-TG1 mice exhibited an increase in infarct volume by $46 \%$ and $34 \%$ at 24 and $72 \mathrm{~h}$ after MCAO/reperfusion, respectively. A similar effect on the infarct size was observed in TRAF6TG2 mice (Fig. 2G,H). Neurological deficits were also more severe in the transgenic lines at both time points (Fig. 2I). Together, these data demonstrated that TRAF6 exacerbates brain damage by directly affecting neurons in $\mathrm{I} / \mathrm{R}$ conditions.

\section{TRAF6 is a prodeath effector regulated by cerebral ischemia} Given that neuronal TRAF6 is specifically induced by $I / R$, that neuron-specific TRAF6 expression potentiates cerebral injury, and that neurons are particularly vulnerable to ischemic stroke (Tymianski, 2011), we investigated whether TRAF6 affects neuronal survival directly. Fluoro-Jade B staining was used to investigate the acute degeneration of neurons and TUNEL staining was conducted simultaneously to identify apoptotic cells after cerebral I/R (Fig. 3A). Compared with TRAF6-floxed mice, TRAF6-KO mice showed a dramatic decrease in the number of Fluoro-Jade B-positive neurons and TUNEL-positive neurons at $24 \mathrm{~h}$ after I/R (Fig. 3A). In contrast, TRAF6 overexpression rendered neurons more vulnerable to cell death (Fig. $3 A$ ). Therefore, TRAF6 is critical for I/R-induced neuronal degeneration and apoptosis. To further investigate this phenomenon, we evaluated the prodeath effect of TRAF6 in cultured rat primary neurons in vitro by infecting these cells with either AdshTRAF6, which decreased TRAF6 expression by 60\% (data not shown), or its scramble control AdshRNA. Indeed, TRAF6-knock-down neurons were more resistant to OGD-induced cell death as evidenced by the significantly enhanced cell viability and decreased LDH release (Fig. 3B). In contrast, TRAF6 overexpression via adenoviral infection (Ad-TRAF6) rendered the neurons more vulnerable to OGD-induced cell death (Fig. 3C). In the brains from TRAF6-KO mice, the mRNA levels of proapoptotic genes (Fas, Fasl, Bax, and Bad) were significantly downregulated, whereas the levels of the anti-apoptotic protein Bcl-2 were upregulated (Fig. 3D). This effect was reversed after TRAF6 overexpression (Fig. 3E). Furthermore, Western blot analysis showed that $\mathrm{Bcl}-2$ expression was decreased and the expression levels of the proapoptotic protein Bax and cleaved-caspase 3 were increased in TRAF $6^{\text {flox/flox }}$ and WT mice at $6 \mathrm{~h}$ after I/R compared with the levels in sham controls (Fig. $3 F$ ). However, these changes were attenuated significantly in TRAF6-KO mice (Fig. $3 F$ ) and en-

$\leftarrow$

(Figure legend continued.) for TRAF6-TG, ${ }^{*} p<0.0001$ vs DMSO, \#p $=0.0250$ vs WT $(C)$ and neurological deficit scores, $n=12$ per group, ANOVA, $F_{(3,44)}=17.550$, for WT ${ }^{*} p=0.0122$ vs DMS0, for TRAF6-TG, ${ }^{*} p<0.0001$ v DMS0, $\# p=0.0170$ vs WT (D) at $24 \mathrm{~h}$ after $\mathrm{l} / \mathrm{R}, n=6-8$ per group]. $E$, Left, Fluoro Jade $B$ and TUNEL were assessed in brain sections of the WT and TRAF6-TG mice treated with NSC23766 and DMSO. Right, Quantification of Fluoro Jade B-positive cell $\left[n=3-5\right.$ per group, ANOVA, $F_{(3,13)}=47.344$, for WT ${ }^{*} p=0.0014$ vs DMSO, for TRAF6-TG, ${ }^{*} p<0.0001$ vs DMSO, $\# p=0.0001$ vs WT. (top right) and TUNEL-positive cell, $n=$ $3-5$ per group, ANOVA, $F_{(3,13)}=43.685$, for WT ${ }^{*} p=0.0014$ vs DMSO, for TRAF6-TG, ${ }^{*} p=$ 0.0080 vs DMSO, $\# p<0.0001$ vs WT (bottom right)]. Scale bars, $50 \mu \mathrm{m}$. $F, G$, Western blot analysis (left) and quantification (right) of the indicated proteins in the WT and TRAF6-TG mice treated with NSC23766 or DMSO ( $n=3-4$ per group, ANOVA, ${ }^{* *} p<0.01,{ }^{* * *} p<0.001$ vs DMSO; \#p $<0.05$, \#\#p $<0.01$, \#\#p $<0.001$ vs WT mice). hanced in TRAF6-TG mice compared with TRAF6 ${ }^{\text {flox/flox }}$ and WT mice, respectively (Fig. $3 F$ ). Moreover, the temporal expression patterns of these proteins were similar in OGDtreated primary neurons infected with either AdshTRAF6 or Ad-TRAF6 (Fig. 3G). Together, these data indicated that TRAF6 accelerates acute neuronal degeneration in response to cerebral I/R injury.

\section{TRAF6 activates the NF- $\kappa \mathrm{B}$ proinflammatory signaling pathway}

Inflammation contributes to the pathophysiology of cerebrovascular diseases, particularly stroke caused by arterial occlusion and ischemic stroke (Moskowitz et al., 2010; Iadecola and Anrather, 2011). Therefore, we evaluated the mRNA expression of proinflammatory mediators such as TNF- $\alpha$, monocyte chemoattractant protein-1 (MCP-1), and IL-1 $\beta$ in the brains of TRAF6-KO and TRAF6-TG mice at $24 \mathrm{~h}$ after I/R. The expression of these cytokines was significantly lower in TRAF6-KO mice and significantly higher in TRAF6-TG mice than their respective littermate controls (Fig. $4 A$ ). NF- $\kappa$ B is a transcription factor that plays a key role in mediating the expression of a variety of genes involved in inflammatory responses during ischemic stroke (Nurmi et al., 2004). Western blotting showed that NF- $\kappa$ B was activated in the cerebrum after I/R injury, as demonstrated by the potentiated phosphorylation of $\mathrm{I} \kappa \mathrm{B} \alpha$, IKK $\beta$, and p65 (Fig. $4 B$ ). In addition, TRAF6 expression in neurons positively regulated this effect in mice during I/R (Fig. 4B). Moreover, activation of the NF- $\kappa \mathrm{B}$ signaling pathway was positively regulated by TRAF6 expression in vitro (Fig. $4 C$ ), suggesting that NF- $\kappa \mathrm{B}-$ mediated inflammation is a downstream target of TRAF6 in ischemic stroke.

\section{TRAF6 enhances oxidative stress after ischemic stroke}

Oxidative stress occurs because of an imbalance between prooxidant and anti-oxidant activities, resulting in excessive production of reactive oxygen species, important mediators of tissue injury during acute ischemic stroke (Allen and Bayraktutan, 2009). To analyze the changes in oxidative stress during ischemia, dihydroethidium (DHE) fluorescent staining was performed to analyze superoxide generation (Fig. 5A); 4-hydroxynonenal (4HNE) fluorescent staining was performed to analyze lipid peroxidation (Fig. 5B); and 8-hydroxy-2 deoxyguanosine (8-OHdG) fluorescent staining was performed to analyze oxidative DNA (Fig. 5C) (Imai et al., 2001; Kawai et al., 2011). The number of DHE-, 4-HNE-, and 8-OHdG-positive cells was significantly decreased in TRAF6-KO mice compared with TRAF6-floxed mice, whereas tissue from TRAF6-TG mice exhibited a pro-oxidative effect (Fig. 5A-C). Next, we evaluated the mRNA levels of the anti-oxidant transcriptional factor Nrf2 and its effectors, glutathione peroxidase and manganese superoxide dismutase, as well as the pro-oxidant NADPH oxidase subunits p47-phox, p67phox, and gp91-phox in mouse brains $24 \mathrm{~h}$ after I/R (Fig. 5D) (Li et al., 2006). TRAF6 knock-out significantly decreased the mRNA levels of NADPH oxidase subunits and increased the mRNA levels of Nrf2 and its downstream targets, whereas TRAF6 overexpression exerted the opposite effects (Fig. $5 D$ ). In agreement with these observations, the results of the immunoblotting assays detecting p47-phox, p67-phox, and HO-1 showed similar trends in the protein expression patterns both in vivo (Fig. $5 E$ ) and in vitro (Fig. 5F). Therefore, TRAF6 leads to significantly increased oxidative stress after cerebral I/R. 
A

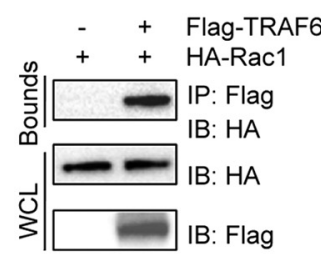

B

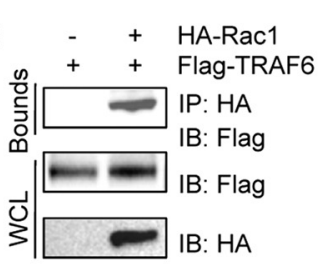

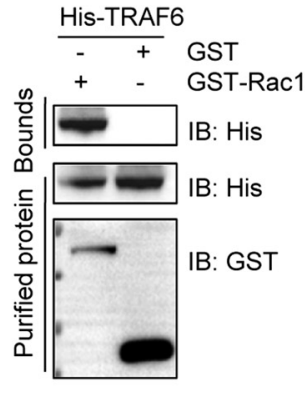

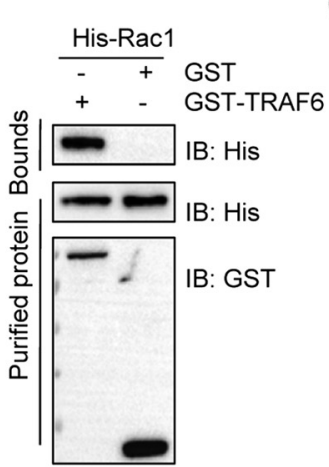

C $+\ldots+\ldots$ - HA-Rac1

$-+\cdot++$ HA-Rac1(T17N)

- - + - + + HA-Rac1(G12V)

- - + + + Flag-TRAF6
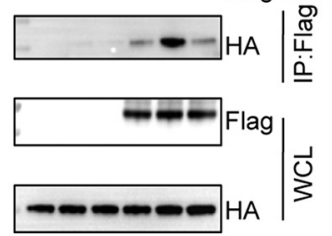

D

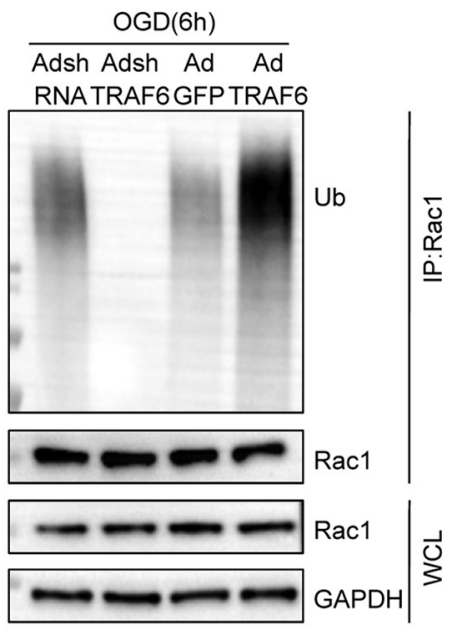

G

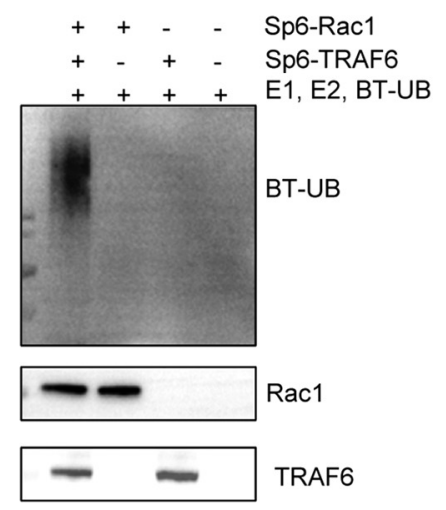

E

$$
\begin{array}{llll}
+ & + & \text { Myc-Ub } \\
- & + & + & \text { HA-Rac1 } \\
- & - & + & \text { Flag-TRAF6 }
\end{array}
$$

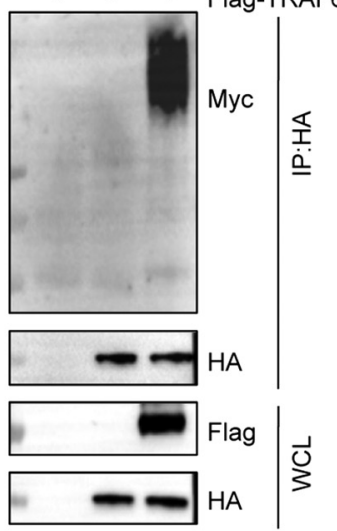

H

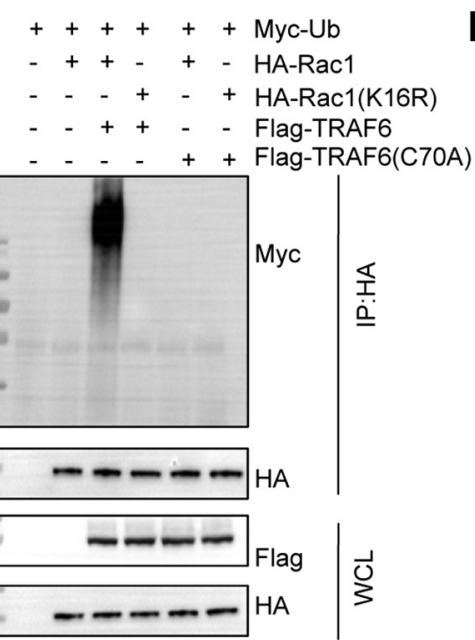

$\mathbf{F}$

$$
\begin{aligned}
& +++\quad+\text { Myc-Ub } \\
& -+++ \text { HA-Rac1 } \\
& -\quad+\quad-\text { Flag-TRAF6 } \\
& -\quad-\quad+\text { Flag-TRAF6(C70A) }
\end{aligned}
$$

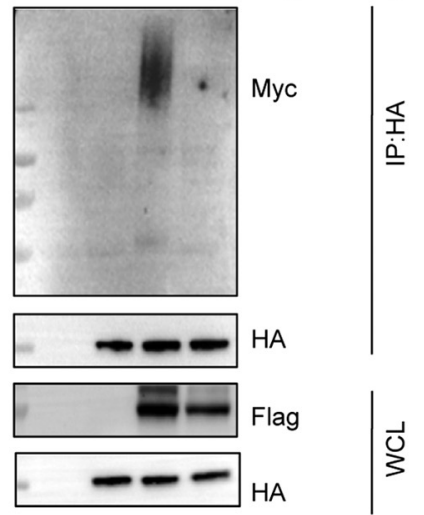

HA-Rac1(WT) HA-Rac1(K16R)

$$
\begin{aligned}
& ++ \text { - + - Flag-TRAF6(WT) } \\
& -\quad+\quad-\quad+\text { Flag-TRAF6(C70A) }
\end{aligned}
$$

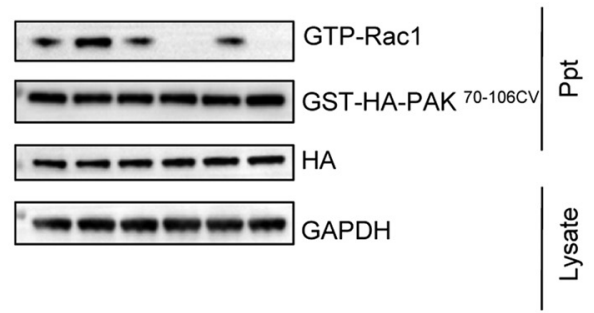

Figure 8. TRAF6 regulates Rac1 activation through direct physical interaction and ubiquitination. A, Coimmunoprecipitation of TRAF6 and Rac1. Primary neurons were coinfected with either Flag-tagged TRAF6 and HA-tagged Rac1 or Flag-tagged Rac1 and HA-tagged TRAF6. Lysates were immunoprecipitated with anti-Flag and analyzed by using immunoblotting with anti-HA or anti-Flag antibodies. B, Immunoblotting analysis of the GST pull-down of either His-tagged TRAF6 with GST-Rac1 or His-tagged Rac1 with GST-TRAF6. C, Immunoblot analysis of total lysates (bottom) and anti-Flag immunoprecipitates (top) of 293T cells expressing various combinations of HA-tagged WT Rac1, HA-Rac1G12V, or HA-Rac1T17N and Flag-tagged TRAF6. D, Primary neurons infected with AdshRNA, AdshTRAF6, or AdGFP and AdTRAF6 were stimulated with OGD for $6 \mathrm{~h}$, immunoprecipitated with anti-Rac1 antibody, and blotted with anti-Ub antibody. $\boldsymbol{E}$, HEK293T cells cotransfected with HA-Rac1, Myc-Ub, and Flag-TRAF6 plasmids were immunoprecipitated with an anti-HA antibody and subjected to Western blotting with an anti-Myc antibody. $F$, HEK293T cells cotransfected with HA-Rac1, Myc-Ub, and either TRAF6 (WT) or TRAF6 (C70A) plasmids were subjected to immunoprecipitation with anti-HA antibody followed by Western blotting with anti-Myc-Ub antibody. G, Rac1 proteins were incubated with E1, E2, and biotinylated-Ub (Bt-Ub) in the presence or absence of TRAF6 proteins to measure the in vitro ubiquitination of Rac1. H, HEK293T cells cotransfected with Myc-Ub, HA-Rac1 (WT) or HA-Rac1 (K16R) and Flag-TRAF6 (WT) or TRAF6 (C70A) plasmids were subjected to immunoprecipitation with an anti-HA antibody followed by Western blotting with an anti-myc antibody. I, Cell lysates from 293T cells expressing Flag-TRAF6 and either HA-Rac1 (WT) or HA-Rac1 (K16R) as indicated were incubated with GST-PAK70-106 (GST-PAK). The association of active (GTP-bound) Rac1 with GST-PAK70-106 was determined via immunoblotting for Rac1. 


\section{TRAF6 promotes Rac1 phosphorylation and activation directly}

On the basis of the observation that TRAF6 promotes neuronal death, NF- $\kappa \mathrm{B}$-mediated inflammation and NADPH oxidasemediated oxidative stress after cerebral I/R injury, we hypothesized that TRAF6 might serve as a key upstream regulator of these molecular pathways through interacting with an unidentified target. Rac1, a member of the Rho GTPase family, has been reported to regulate pathways that mediate the inflammatory response and ROS-mediated cell death by interacting with NF- $\kappa \mathrm{B}$ and NADPH oxidase (Heasman and Ridley, 2008; Bid et al., 2013). We found that Racl activation was significantly increased after I/R injury and this activation was decreased by TRAF6 ablation but enhanced by TRAF6 overexpression in both mouse brains (Fig. 6A) and cultured neurons (Fig. $6 B$ ). Furthermore, the abundance of GTP-bound Racl was much lower in cortical neurons from TRAF6-KO mice but higher in the neurons from TRAF6-TG mice after I/R injury compared with controls (Fig. 6C). Immunofluorescence staining for p-Racl and NeuN in the penumbral tissues from TRAF6-KO and TRAF6-TG mice further demonstrated TRAF6-mediated activation of Rac1 (Fig. 6D). Collectively, these data indicated that Racl activation may be responsible for adverse oxidative stress and inflammatory response induced by TRAF6 during ischemic stroke.

\section{Inhibiting Rac1 rescues TRAF6-mediated cerebral injury in stroke}

To further confirm that Racl activation is required in TRAF6mediated neuronal death, TRAF6-TG and WT mice were treated with either NSC23766, a Rac1-specific inhibitor (Gao et al., 2004), or DMSO. As shown in Figure 7A, NSC23766 successfully inhibited Racl phosphorylation after cerebral I/R injury in both WT and TRAF6-TG mice. Blocking Racl activation attenuated $\mathrm{MCAO} /$ reperfusion-induced cerebral injury markedly (Fig. $7 B-D$ ) in WT mice. Furthermore, NSC23766 treatment abolished the aggravation of the infarct sizes and neurological deficits in TRAF6-TG mice (Fig. 7B-D). More importantly, blocking Rac1 activation also counteracted TRAF6-mediated neuronal death and apoptosis (Fig. 7E). In addition, treating TRAF6-TG and WT mice with NSC23766 resulted in significantly lower expression levels of NADPH oxidase subunits, pro-apoptotic signaling pathway components, and NF- $\kappa \mathrm{B}$-mediated inflammation, whereas higher HO-1, Caspase3, and Bcl-2 expression compared with the corresponding control littermates (Fig. $7 F, G$ ). Together, these data demonstrated that Rac1 inhibition effectively ameliorates TRAF6-mediated cerebral injury in ischemic stroke.

\section{TRAF6 interacts with Rac1 and mediates its ubiquitination}

Next, to explore how TRAF6 activates Rac1, we transfected Flagtagged Rac1 and HA-tagged TRAF6 into HEK293T cells and found that TRAF6 coimmunoprecipitated with Racl and vice versa (Fig. 8A). This TRAF6-Rac1 interaction was further supported by the results of the glutathione S-transferase pull-down assay (Fig. 8B). To identify which type of Racl interacts with TRAF6, we incubated purified WT Rac1, constitutively active form of Racl ( $\operatorname{Racl}^{\mathrm{G} 12 \mathrm{~V}}$ ) or inactive form of Rac1 $\left(\operatorname{Racl}^{\mathrm{T} 17 \mathrm{~N}}\right)$ with TRAF6. The results showed that TRAF6 interacts selectively with inactive $\mathrm{Racl}^{\mathrm{T} 17 \mathrm{~N}}$, but not active Rac1 ${ }^{\mathrm{G} 12 \mathrm{~V}}$ or WT Rac1 (Fig. 8C).

The direct interaction between TRAF6 and Rac1, as well as the increased levels of phosphorylated Rac1 during TRAF6-mediated cerebral injury, promoted us to investigate the events that mediate TRAF6-Rac1 interaction and Racl activation. It has been re- ported that TRAF6 functions with a ubiquitin-conjugating (E2) complex and catalyzes the synthesis of Lys63 (K63)-conjugated polyubiquitin chains on its target proteins and that Racl ubiquitination is crucial for its phosphorylation and subsequent activation (Jiang and Chen, 2011; Geng et al., 2015). We first measured Racl ubiquitination in primary neurons subjected to OGD/reperfusion. Figure $8 D$ shows that Racl ubiquitination was abolished when TRAF6 was absent but was increased when TRAF6 was overexpressed. Studies on 293T cells transfected with HA-Rac1 with or without Flag-TRAF6 plasmids further confirmed the potentiating effect of TRAF6 on Racl ubiquitination (Fig. 8E). Notably, blocking the E3 ubiquitin ligase activity (C70A) of TRAF6 blocked its ability to enhance Racl ubiquitination (Fig. 8F). When Rac1 was coincubated with E1, E2, and biotinylated-Ub in the presence or absence of TRAF6, Rac1 ubiquitination was induced directly in the presence of TRAF6 (Fig. $8 G$ ). Cotransfection of 293 T cells with vectors expressing FlagTRAF6 and either HA-Rac1 or HA-Rac1K16R demonstrated that Lys 16 was the ubiquitin acceptor site (Fig. $8 H$ ) and was crucial for TRAF6-induced activation of Rac1 (Fig. 8I). These results demonstrated that TRAF6 binds directly to Rac1 and catalyzes K63-linked polyubiquitination of Rac1.

\section{E3 ligase activity of TRAF6 is required for cerebral I/R-induced neuron damage}

To determine whether TRAF6-induced Racl ubiquitination is essential for TRAF6-mediated cerebral injury, adenovirus carrying a catalytically inactive TRAF6 mutant (C68A, H70A; referred to as "TRAF6-M") was generated and transfected into primary neurons. Cells infected with Ad-TRAF6-M did not exhibit increased susceptibility to OGD-induced cell death compared with the AdTRAF6-infected group (Fig. 9A). More importantly, we observed that TRAF6-M could not promote the phosphorylation of Rac1 in cultured neurons challenged with OGD/reperfusion (Fig. 9B). Accordingly, the capacity of TRAF6-mediated activation to promote apoptosis, NADPH oxidase signaling, and NF$\kappa \mathrm{B}$-mediated inflammation were abolished in cells expressing catalytically inactive TRAF6 (Fig. 9B, C). We next examined the biological function of the E3 ligase activity of TRAF6 in vivo. Intracranial injection of AdTRAF6 in mice resulted in an adverse stroke outcome, but this effect was blunted by the loss of the E3 ligase activity of TRAF6 (Fig. 9D-F), indicating that the E3 ligase activity of TRAF6 is required for its ability to mediate the cerebral I/R-induced neuron damage.

\section{Discussion}

Despite extensive investigations of the mechanisms of ischemic cerebral injury, little progress has been made in translating these findings into clinical practice. Multiple pathophysiological events and the complex molecular mechanisms activated during cerebral I/R injury have impeded the translation of potential therapeutic targets into medicine (Moskowitz et al., 2010b). Therefore, a single therapeutic target that could exert multiple effects on stroke outcomes might provide a more promising strategy (Savitz and Fisher, 2007). The present study revealed that TRAF6 is a key modulator of ischemic signaling cascades involved in inflammation, as well as oxidative stress and neuronal death, during cerebral I/R injury.

We showed that TRAF6 expression is induced in neurons after I/R injury. TRAF6 overexpression in neurons led to exacerbated cerebral damage, whereas loss of TRAF6 expression was neuroprotective. Mechanistically, neuronal TRAF6 interacts with inactive (GDP-bound) Rac1, mediates K63-linked ubiquitination 

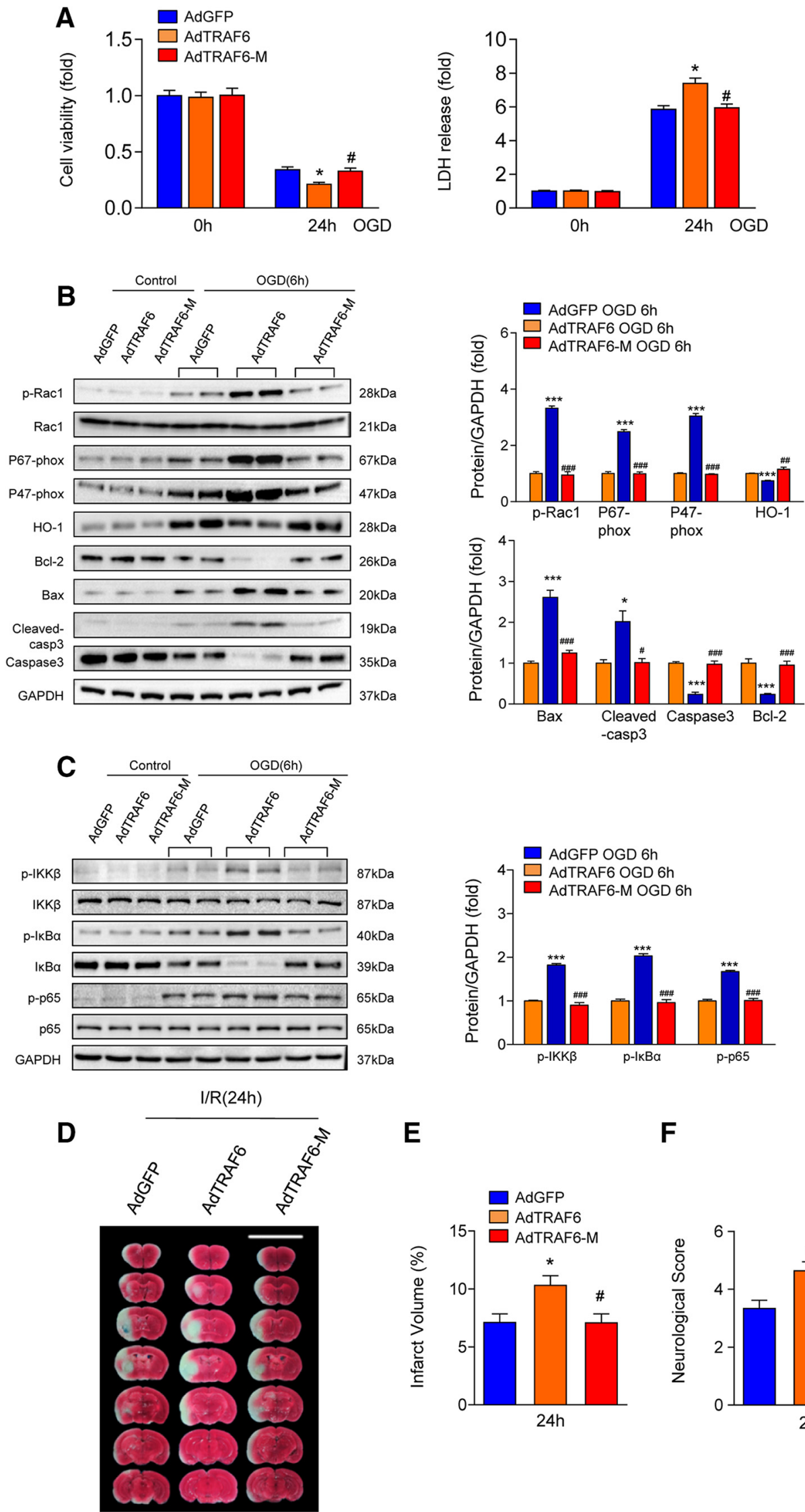

$\mathbf{E}$

$\mathbf{F}$
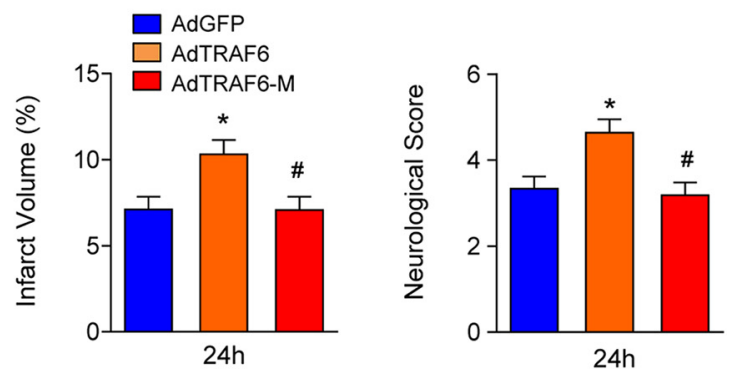

Figure 9. TRAF6-induced Rac1 ubiquitination is essential for ischemic stroke. Primary neurons were transduced with AdGFP, AdTRAF6, or TRAF6-M. A, After cells were subjected to $24 \mathrm{~h}$ OGD/reperfusion, cell viability (left) and LDH release (right) were examined ( $n=9$ per group, ANOVA, for cell viability, $F_{(3,32)}=9.492,{ }^{*} p=0.0006$ vs AdGFP, \#p $=0.0017$ vs AdTRAF6; for LDH release, $F_{(3,32)}=11.346,{ }^{*} p=0.0003$ vs AdGFP, \#p $=0.0005$ vs AdTRAF6). $B$, C, After cells were subjected to $6 \mathrm{~h}$ of $0 \mathrm{GD}$ /reperfusion, Western blot analysis (Figure legend continues.) 
of Rac1 after GTP "charging," and then dissociates from GTPbound Racl. The ubiquitination of Racl thus augments the binding of GTP to Racl and potentiates the phosphorylation and activation of Rac1. Activated Racl subsequently activates NF- $\kappa$ B and Nox2, leading to increased inflammation, oxidative stress, and neuronal death (Fig. 10). These combined adverse effects results in enlarged cerebral infarctions and increased neurological deficits after stroke.

Cerebral I/R injury induces various cell death mechanisms, including excitotoxicity, oxidative stress, inflammation, and apoptosis-like cell death, all of which lead to catastrophic histological loss and functional damage. Our previous serial studies have demonstrated that innate immune signaling networks can affect the progression of cerebral I/R injury by functioning in nonimmune cells (Zhang et al., 2015). TRAFs play indispensable roles in regulating innate and adaptive immunity, function as important adaptor molecules in various signaling pathways, and possess a broad spectrum of substrates (Sebban-Benin et al., 2007; Alvarez et al., 2010; Mu et al., 2011). Recently, several TRAFs have been demonstrated to be important regulators during cerebral I/R injury. After cerebral I/R, TRAF1 promotes neuroapoptosis by activating the JNK prodeath pathway and inhibiting Akt cell survival signaling ( $\mathrm{Lu}$ et al., 2013). TRAF2 can activate the JNK1/2, p38 MAPK (Xu et al., 2006), or NF- $\kappa$ B pathways (Su et al., 2017) to induce apoptosis and inflammation in I/R injured brain. TRAF3 binds to TAK1 and potentiates TAK1-dependent activation of the NF- $\kappa \mathrm{B}, \mathrm{Rac}-1$, and JNK signaling pathways to regulate inflammation, oxidative stress, and neuronal survival (Gong et al., 2015). And TRAF5 markedly aggravates neuronal apoptosis, blood-brain Bbrrier degradation, and postischemic inflammation by enhancing Akt/FoxO1 and NF- $\kappa \mathrm{B}$ signaling (Wang et al., 2013; Tao et al., 2015). These previous studies revealed the important but distinct role of different TRAF molecules in regulating the pathology of ischemic stroke. In contrast to other TRAFs, TRAF6 uses a distinct interaction motif and acts as a convergence point for the TNFR and TLR families (Song et al., 1997; Muzio et al., 1998; Ye et al., 2002). Here, we demonstrated that TRAF6 promotes cerebral I/R injury by potentiating NF- $\kappa$ B-mediated inflammation, Nox2-mediated oxidative stress, and incidental neuronal damage by interacting directly with Racl. These results further indicate the nonidentical role of different TRAFs in ischemia stroke.

Racl functions as a binary switch and participates in a wide variety of signaling pathways involved in ischemic stroke, including the regulation of inflammatory response by interacting with $\mathrm{NF}-\kappa \mathrm{B}$ and oxidative stress by interacting with NADPH oxidase (Heasman and Ridley, 2008; Bid et al., 2013). Knocking out or pharmacological inhibition of Racl could attenuate brain injury and edema after cerebral ischemia (Sawada et al., 2009; Raz et al., 2010; Liao et al., 2014; Meng et al., 2015). In the current study, using neuron-specific genetic manipulation, we provided robust evidence that TRAF6 promotes Racl activation during cerebral I/R injury. Furthermore, in our study, inhibiting Racl activation with a Rac1-specific inhibitor (NSC23766) significantly atten-

$\leftarrow$

(Figure legend continued.) (left) and relative quantification (right) of the indicated proteins were conducted $\left(n=3-5\right.$, ANOVA, ${ }^{*} p<0.05,{ }^{* *} p<0.01,{ }^{* * *} p<0.001$ vs AdGFP; $\# p<0.05$, $\# \# p<0.01$, \#\#\#p $<0.001$ vs AdTRAF6). $\boldsymbol{D}-\boldsymbol{F}$, TTC-stained brain sections ( $\boldsymbol{D}$ ) and quantification of the infarct volumes $\left(n=12\right.$ per group, $\operatorname{ANOVA}, F_{(2,31)}=5.611,{ }^{*} p=0.0114$ vs AdGFP, $\# p=$ 0.0053 vs AdTRAF6) ( $\boldsymbol{E})$ and neurological scores, $n=5-7$ per group, ANOVA, $F_{(2,32)}=7.140$, ${ }^{*} p=0.0192$ vs AdGFP, $\# p=0.0205$ vs AdTRAF6) ( $F$ ) from AdGFP, AdTRAF6, and AdTRAF6-M mice are shown.

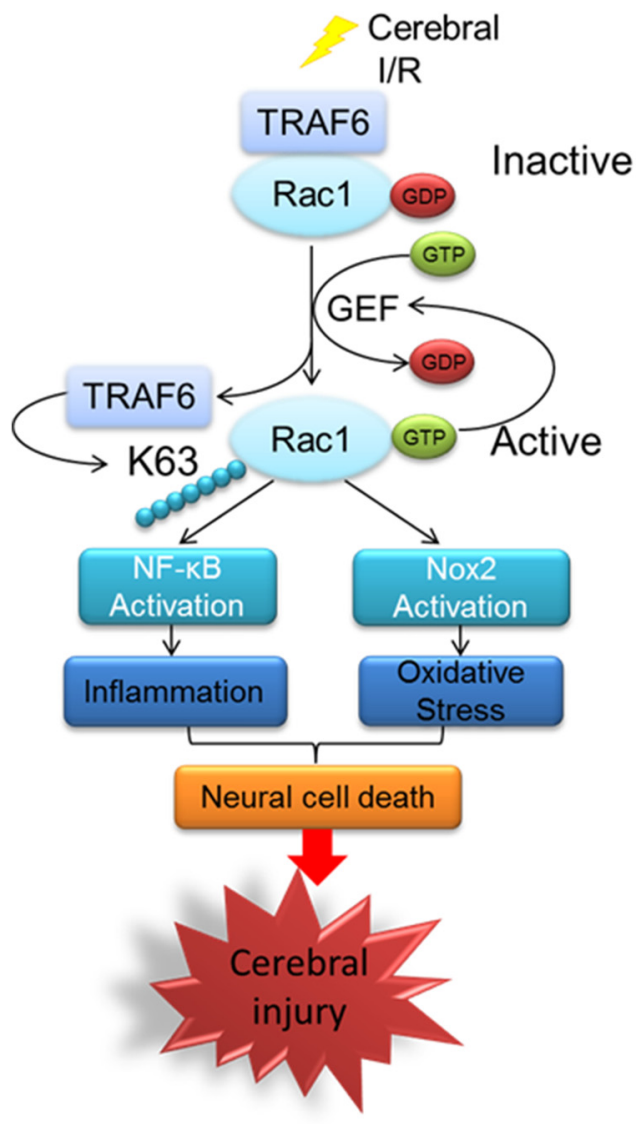

Figure 10. Schematic summary. After cerebral I/R injury, induced TRAF6 interacts directly with GDP-bound Rac1. Rac1 then undergoes K63-linked ubiquitinated by TRAF6 once "charged" with GTP, which augments GTP "charging" of Rac1 and potentiates the activation of Rac1. TRAF6 disassociates from activated Rac1, the latter subsequently activates NF- $\kappa$ B and Nox2, which in turn induce inflammation, oxidative stress, and neuronal cell death and ultimately contribute to cerebral injury.

uated I/R-induced neuronal damage in WT mice. More importantly, NSC23766 treatment largely abolished the neuronal damage caused by TRAF6 overexpression. Therefore, Rac1 activation is crucial in the pathology of ischemic stroke and is the primary mediator of the devastating effects of TRAF6 on brain I/R injury.

One of the most significant findings of this study is that Racl is activated by TRAF6 via direct interaction and ubiquitination in ischemic stroke. Previous studies revealed that the "GTP-charged" active form of the Rho-family GTPases is required for activation of NADPH oxidase (Bokoch and Diebold, 2002). In general, Rac1 activity is spatially and temporally controlled by the opposing activities of guanine nucleotide exchange factors including VAV1, VAV2, DBL, and TIAM1 (Rossman et al., 2005; Bid et al., 2013), which exchange GDP for GTP and activate Racl and the classical GTPase-activating proteins. However, it is unclear how $\mathrm{Racl}$ is activated in response to ischemic stroke. We demonstrate here that neuronal TRAF6 can potentiate the activation of Rac1 by interacting with and ubiquitinating Rac1 directly. Once the E3 ubiquitin ligase activity of TRAF6 was blocked, it lost its ability to enhance Rac1 ubiquitination and activation. These findings indicate that TRAF6-mediated Lys63-linked ubiquitination of Racl is crucial for Racl activation.

In summary, we demonstrate that endogenous TRAF6 is an essential molecular switch for the resulting pathology of ischemic stroke in a manner dependent on the TRAF6-Rac1 interaction 
and TRAF6-induced ubiquitination of GTP-bound Rac1. Given that all clinical trials focused on inhibiting a single pathological event have failed (Savitz and Fisher, 2007), a treatment that can target the complex molecular networks responsible for the pathology of ischemic stroke would be preferred in developing competent therapeutic strategies. The broad-spectrum effects of the TRAF6-Rac1 axis identified in the present study may strengthen its potential as a promising target for treating ischemic stroke.

\section{References}

Allen CL, Bayraktutan U (2009) Oxidative stress and its role in the pathogenesis of ischaemic stroke. Int J Stroke 4:461-470. CrossRef Medline

Alvarez SE, Harikumar KB, Hait NC, Allegood J, Strub GM, Kim EY, Maceyka M, Jiang H, Luo C, Kordula T, Milstien S, Spiegel S (2010) Sphingosine1-phosphate is a missing cofactor for the E3 ubiquitin ligase TRAF2. Nature 465:1084-1088. CrossRef Medline

Ankarcrona M, Dypbukt JM, Bonfoco E, Zhivotovsky B, Orrenius S, Lipton SA, Nicotera P (1995) Glutamate-induced neuronal death: a succession of necrosis or apoptosis depending on mitochondrial function. Neuron 15:961-973. CrossRef Medline

Bid HK, Roberts RD, Manchanda PK, Houghton PJ (2013) RAC1: an emerging therapeutic option for targeting cancer angiogenesis and metastasis. Mol Cancer Ther 12:1925-1934. CrossRef Medline

Bokoch GM, Diebold BA (2002) Current molecular models for NADPH oxidase regulation by Rac GTPase. Blood 100:2692-2696. CrossRef Medline

Bonita R (1992) Epidemiology of stroke. Lancet 339:342-344. CrossRef Medline

Broughton BR, Reutens DC, Sobey CG (2009) Apoptotic mechanisms after cerebral ischemia. Stroke 40:e331-e339. CrossRef Medline

Casanova E, Fehsenfeld S, Mantamadiotis T, Lemberger T, Greiner E, Stewart AF, Schütz G (2001) A CaMKIIalpha iCre BAC allows brain-specific gene inactivation. Genesis 31:37-42. CrossRef Medline

Engel O, Kolodziej S, Dirnagl U, Prinz V (2011) Modeling stroke in mice: middle cerebral artery occlusion with the filament model. J Vis Exp 47: pii: 2423. CrossRef Medline

Fann DY, Lim YA, Cheng YL, Lok KZ, Chunduri P, Baik SH, Drummond GR, Dheen ST, Sobey CG, Jo DG, Chen CL, Arumugam TV (2017) Evidence that NF-kappaB and MAPK signaling promotes NLRP inflammasome neurons following ischemic stroke. Mol Neurobiol. Advance online publication. CrossRef Medline

Feigin VL, Lawes CM, Bennett DA, Anderson CS (2003) Stroke epidemiology: a review of population-based studies of incidence, prevalence, and case-fatality in the late 20th century. Lancet Neurol 2:43-53. CrossRef Medline

Gao Y, Dickerson JB, Guo F, Zheng J, Zheng Y (2004) Rational design and characterization of a Rac GTPase-specific small molecule inhibitor. Proc Natl Acad Sci U S A 101:7618-7623. CrossRef Medline

Geng J, et al. (2015) Kinases Mst1 and Mst2 positively regulate phagocytic induction of reactive oxygen species and bactericidal activity. Nat Immunol 16:1142-1152. CrossRef Medline

Gong J, Li ZZ, Guo S, Zhang XJ, Zhang P, Zhao GN, Gao L, Zhang Y, Zheng A, Zhang XF, Xiang M, Li H (2015) Neuron-specific tumor necrosis factor receptor-associated factor 3 is a central regulator of neuronal death in acute ischemic stroke. Hypertension 66:604-616. CrossRef Medline

Heasman SJ, Ridley AJ (2008) Mammalian Rho GTPases: new insights into their functions from in vivo studies. Nat Rev Mol Cell Biol 9:690-701. CrossRef Medline

Humphries SE, Morgan L (2004) Genetic risk factors for stroke and carotid atherosclerosis: insights into pathophysiology from candidate gene approaches. Lancet Neurol 3:227-235. CrossRef Medline

Iadecola C, Anrather J (2011) The immunology of stroke: from mechanisms to translation. Nat Med 17:796-808. CrossRef Medline

Imai H, Masayasu H, Dewar D, Graham DI, Macrae IM (2001) Ebselen protects both gray and white matter in a rodent model of focal cerebral ischemia. Stroke 32:2149-2154. CrossRef Medline

Jiang X, Chen ZJ (2011) The role of ubiquitylation in immune defence and pathogen evasion. Nat Rev Immunol 12:35-48. CrossRef Medline

Ji YX, Zhang P, Zhang XJ, Zhao YC, Deng KQ, Jiang X, Wang PX, Huang Z, Li H (2016) The ubiquitin E3 ligase TRAF6 exacerbates pathological car- diac hypertrophy via TAK1-dependent signalling. Nat Commun 7:11267. CrossRef Medline

Kawai H, Deguchi S, Deguchi K, Yamashita T, Ohta Y, Shang J, Tian F, Zhang X, Liu N, Liu W, Ikeda Y, Matsuura T, Abe K (2011) Synergistic benefit of combined amlodipine plus atorvastatin on neuronal damage after stroke in Zucker metabolic rat. Brain Res 1368:317-323. CrossRef Medline

Khoshnam SE, Winlow W, Farzaneh M, Farbood Y, Moghaddam HF (2017) Pathogenic mechanisms following ischemic stroke. Neurol Sci 38:11671186. CrossRef Medline

Kuteeva E, Calza L, Holmberg K, Theodorsson E, Ogren SO, Hökfelt T (2004) Distribution of galanin and galanin transcript in the brain of a galanin-overexpressing transgenic mouse. J Chem Neuroanat 28:185216. CrossRef Medline

Liao J, Ye Z, Huang G, Xu C, Guo Q, Wang E (2014) Delayed treatment with NSC23766 in streptozotocin-induced diabetic rats ameliorates postischemic neuronal apoptosis through suppression of mitochondrial p53 translocation. Neuropharmacology 85:508-516. CrossRef Medline

Li Q, Harraz MM, Zhou W, Zhang LN, Ding W, Zhang Y, Eggleston T, Yeaman C, Banfi B, Engelhardt JF (2006) Nox2 and Rac1 regulate $\mathrm{H} 2 \mathrm{O} 2$-dependent recruitment of TRAF6 to endosomal interleukin-1 receptor complexes. Mol Cell Biol 26:140-154. CrossRef Medline

Lo EH, Dalkara T, Moskowitz MA (2003) Mechanisms, challenges and opportunities in stroke. Nat Rev Neurosci 4:399-415. Medline

Lozano R, et al. (2012) Global and regional mortality from 235 causes of death for 20 age groups in 1990 and 2010: a systematic analysis for the Global Burden of Disease Study 2010. Lancet 380:2095-2128. CrossRef Medline

Lu YY, Li ZZ, Jiang DS, Wang L, Zhang Y, Chen K, Zhang XF, Liu Y, Fan GC, Chen Y, Yang Q, Zhou Y, Zhang XD, Liu DP, Li H (2013) TRAF1 is a critical regulator of cerebral ischaemia-reperfusion injury and neuronal death. Nat Commun 4:2852. CrossRef Medline

Meng S, Su Z, Liu Z, Wang N, Wang Z (2015) Racl contributes to cerebral ischemia reperfusion-induced injury in mice by regulation of Notch2. Neuroscience 306:100-114. CrossRef Medline

Moskowitz MA, Lo EH, Iadecola C (2010) The science of stroke: mechanisms in search of treatments. Neuron 67:181-198. CrossRef Medline

Mu Y, Sundar R, Thakur N, Ekman M, Gudey SK, Yakymovych M, Hermansson A, Dimitriou H, Bengoechea-Alonso MT, Ericsson J, Heldin $\mathrm{CH}$, Landström M (2011) TRAF6 ubiquitinates TGFbeta type I receptor to promote its cleavage and nuclear translocation in cancer. Nat Commun 2:330. CrossRef Medline

Muzio M, Natoli G, Saccani S, Levrero M, Mantovani A (1998) The human toll signaling pathway: divergence of nuclear factor kappaB and JNK/ SAPK activation upstream of tumor necrosis factor receptor-associated factor 6 (TRAF6). J Exp Med 187:2097-2101. CrossRef Medline

Nurmi A, Lindsberg PJ, Koistinaho M, Zhang W, Juettler E, KarjalainenLindsberg ML, Weih F, Frank N, Schwaninger M, Koistinaho J (2004) Nuclear factor-kappaB contributes to infarction after permanent focal ischemia. Stroke 35:987-991. CrossRef Medline

Peel AL, Zolotukhin S, Schrimsher GW, Muzyczka N, Reier PJ (1997) Efficient transduction of green fluorescent protein in spinal cord neurons using adeno-associated virus vectors containing cell type-specific promoters. Gene Ther 4:16-24. CrossRef Medline

Raz L, Zhang QG, Zhou CF, Han D, Gulati P, Yang LC, Yang F, Wang RM, Brann DW (2010) Role of Racl GTPase in NADPH oxidase activation and cognitive impairment following cerebral ischemia in the rat. PLoS One 5:e12606. CrossRef Medline

Rossman KL, Der CJ, Sondek J (2005) GEF means go: turning on RHO GTPases with guanine nucleotide-exchange factors. Nat Rev Mol Cell Biol 6:167-180. Medline

Savitz SI, Fisher M (2007) Future of neuroprotection for acute stroke: in the aftermath of the SAINT trials. Ann Neurol 61:396-402. CrossRef Medline

Sawada N, Kim HH, Moskowitz MA, Liao JK (2009) Racl is a critical mediator of endothelium-derived neurotrophic activity. Sci Signal 2:ra10. CrossRef Medline

Sebban-Benin H, Pescatore A, Fusco F, Pascuale V, Gautheron J, Yamaoka S, Moncla A, Ursini MV, Courtois G (2007) Identification of TRAF6dependent NEMO polyubiquitination sites through analysis of a new NEMO mutation causing incontinentia pigmenti. Hum Mol Genet 16: 2805-2815. CrossRef Medline 
Song HY, Régnier CH, Kirschning CJ, Goeddel DV, Rothe M (1997) Tumor necrosis factor (TNF)-mediated kinase cascades: bifurcation of nuclear factor-kappaB and c-jun N-terminal kinase (JNK/SAPK) pathways at TNF receptor-associated factor 2. Proc Natl Acad Sci U S A 94:97929796. CrossRef Medline

Su D, Cheng Y, Li S, Dai D, Zhang W, Lv M (2017) Sphk1 mediates neuroinflammation and neuronal injury via TRAF2/NF-kappaB pathways in activated microglia in cerebral ischemia reperfusion. J Neuroimmunol 305:35-41. CrossRef Medline

Su L, Chen Z, Yan Y, Liang B, Xie J, Chen Q, Tan J, Gu L (2015) Association between TRAF6 gene polymorphisms and susceptibility of ischemic stroke in southern Chinese Han population. J Mol Neurosci 57:386-392. CrossRef Medline

Tang XN, Zheng Z, Giffard RG, Yenari MA (2011) Significance of marrowderived nicotinamide adenine dinucleotide phosphate oxidase in experimental ischemic stroke. Ann Neurol 70:606-615. CrossRef Medline

Tao X, Sun X, Yin L, Han X, Xu L, Qi Y, Xu Y, Li H, Lin Y, Liu K, Peng J (2015) Dioscin ameliorates cerebral ischemia/reperfusion injury through the downregulation of TLR4 signaling via HMGB-1 inhibition. Free Radic Biol Med 84:103-115. CrossRef Medline

Tobin MK, Bonds JA, Minshall RD, Pelligrino DA, Testai FD, Lazarov O (2014) Neurogenesis and inflammation after ischemic stroke: what is known and where we go from here. J Cereb Blood Flow Metab 34:15731584. CrossRef Medline

Tymianski M (2011) Emerging mechanisms of disrupted cellular signaling in brain ischemia. Nat Neurosci 14:1369-1373. CrossRef Medline

Wang L, Lu Y, Guan H, Jiang D, Guan Y, Zhang X, Nakano H, Zhou Y, Zhang Y, Yang L, Li H (2013) Tumor necrosis factor receptor-associated factor
5 is an essential mediator of ischemic brain infarction. J Neurochem 126: 400-414. CrossRef Medline

Wu D, Lee YC, Liu HC, Yuan RY, Chiou HY, Hung CH, Hu CJ (2013) Identification of TLR downstream pathways in stroke patients. Clin Biochem 46:1058-1064. CrossRef Medline

Xie P (2013) TRAF molecules in cell signaling and in human diseases. J Mol Signal 8:7. CrossRef Medline

Xu Y, Huang S, Liu ZG, Han J (2006) Poly(ADP-ribose) polymerase-1 signaling to mitochondria in necrotic cell death requires RIP1/TRAF2mediated JNK1 activation. J Biol Chem 281:8788-8795. CrossRef Medline

Ye H, Arron JR, Lamothe B, Cirilli M, Kobayashi T, Shevde NK, Segal D, Dzivenu OK, Vologodskaia M, Yim M, Du K, Singh S, Pike JW, Darnay BG, Choi Y, Wu H (2002) Distinct molecular mechanism for initiating TRAF6 signalling. Nature 418:443-447. CrossRef Medline

Yuan P, Liu Z, Liu M, Huang J, Li X, Zhou X (2013) Up-regulated tumor necrosis factor-associated factor 6 level is correlated with apoptosis in the rat cerebral ischemia and reperfusion. Neurol Sci 34:1133-1138. CrossRef Medline

Zhang XJ, Zhang P, Li H (2015) Interferon regulatory factor signalings in cardiometabolic diseases. Hypertension 66:222-247. CrossRef Medline

Zucchelli S, Marcuzzi F, Codrich M, Agostoni E, Vilotti S, Biagioli M, Pinto M, Carnemolla A, Santoro C, Gustincich S, Persichetti F (2011) Tumor necrosis factor receptor-associated factor 6 (TRAF6) associates with huntingtin protein and promotes its atypical ubiquitination to enhance aggregate formation. J Biol Chem 286:25108-25117. CrossRef Medline 